NBER WORKING PAPER SERIES

\title{
DOMESTIC AND MULTILATERAL EFFECTS OF CAPITAL CONTROLS IN EMERGING MARKETS
}

\author{
Gurnain Pasricha \\ Matteo Falagiarda \\ Martin Bijsterbosch \\ Joshua Aizenman \\ Working Paper 20822 \\ http://www.nber.org/papers/w20822 \\ NATIONAL BUREAU OF ECONOMIC RESEARCH \\ 1050 Massachusetts Avenue \\ Cambridge, MA 02138 \\ January 2015, Revised August 2018
}

\begin{abstract}
We would like to thank Thomas Dallaire, Gagandeep Pabla, Bryce Shelton and Derrick Shroeter for excellent research assistance. We would also like to thank two anonymous referees, Damien Cubizol, Rose Cunningham, Michael Ehrmann, Andrea Fracasso, Serdar Kabaca, Rahul Mukherjee, Robert McCauley, seminar participants at Bank of Canada, Bank for International Settlements, International Monetary Fund, Inter-American Development Bank, the Central Bank of Republic of Turkey and Bank of England joint G20 workshop on "International Monetary and Financial System: short-term challenges, long-term solutions", the 13th Research Meeting of NIPFP-DEA Research Program at Neemrana, India, the 13th INFINITI conference on International Finance, the 2016 Annual Conference of the Royal Economic Society and the EMG-ECB Workshop on Global Liquidity and its International Implications held in April 2016, for helpful comments and suggestions. The views expressed in this paper are those of the authors. No responsibility for them should be attributed to the Bank of Canada, the European Central Bank or the NBER. This research did not receive any specific grant from funding agencies in the public, commercial, or not-for-profit sectors.
\end{abstract}

NBER working papers are circulated for discussion and comment purposes. They have not been peer-reviewed or been subject to the review by the NBER Board of Directors that accompanies official NBER publications.

(C) 2015 by Gurnain Pasricha, Matteo Falagiarda, Martin Bijsterbosch, and Joshua Aizenman. All rights reserved. Short sections of text, not to exceed two paragraphs, may be quoted without explicit permission provided that full credit, including $\odot$ notice, is given to the source. 
Domestic and Multilateral Effects of Capital Controls in Emerging Markets

Gurnain Pasricha, Matteo Falagiarda, Martin Bijsterbosch, and Joshua Aizenman

NBER Working Paper No. 20822

January 2015, Revised August 2018

JEL No. F32,F41,F42

\section{ABSTRACT}

Using a novel, high frequency dataset on capital control actions in 16 emerging market economies (EMEs) from 2001 to 2012, we provide new insights into the domestic and multilateral effects of capital controls. Increases in capital account openness reduce monetary policy autonomy and increase exchange rate stability, confirming the constraints of the monetary policy trilemma. Both gross in- and outflows rise, while the effect on net capital flows is ambiguous. Tighter capital inflow restrictions generated significant spillovers, especially in the post-2008 environment of abundant global liquidity. We also find evidence of a domestic policy response to foreign capital control changes in countries that are affected by these spillovers.

\author{
Gurnain Pasricha \\ Bank of Canada \\ 234 Wellington Street, \\ Ottawa, ON K1A 0G9 \\ Canada \\ gpasricha@bankofcanada.ca \\ Matteo Falagiarda \\ Frankfurt \\ Europe \\ matteo.falagiarda@ecb.europa.eu
}

\author{
Martin Bijsterbosch \\ Frankfurt \\ Europe \\ martin.bijsterbosch@ecb.europa.eu \\ Joshua Aizenman \\ Economics and SIR \\ USC \\ University Park \\ Los Angeles, CA 90089-0043 \\ and NBER \\ aizenman@usc.edu
}

A Data appendices is available at http://www.nber.org/data-appendix/w20822 


\section{Introduction}

As the size and volatility of international capital flows have increased over the past decade, the policy debate about how to manage these flows has intensified. A key question being debated is whether capital controls are useful as tools to manage capital inflow surges. Proponents argue that capital controls are effective in stemming large and volatile inflows in recipient countries and can therefore be valid tools of macroeconomic and macro-prudential management (IMF, 2011a). However, the empirical evidence of effectiveness of capital controls in meeting domestic policy objectives is mixed. ${ }^{3}$

While the evidence on the domestic effects of capital controls may be limited, what makes capital controls an issue of heated international debate is the concern that these controls may have multilateral, i.e. spillover effects. They may distort the global allocation of resources by diverting flows to other economies and can be used as tools in a currency war to gain an unfair competitive advantage. Just as concerns have been raised about spillovers of nonconventional monetary policies in advanced economies on emerging market economies (EMEs), so have policy-makers in the latter countries raised concerns about the use of capital controls in other EMEs.

We provide new evidence on both aspects of this debate: First, we investigate whether capital controls are effective in influencing gross flows using a model specification based on the monetary policy trilemma. Second, we examine whether capital control actions have spillover effects and whether these have become more important in the post-global financial crisis environment of abundant global liquidity. In order to address these questions, we use a novel dataset of 782 policy changes or capital control actions (CCAs) in 16 EMEs over the period 1 January 2001-31 December 2012, along with information about their precise implementation dates.

We contribute to the literature in three ways. First, we use a new, high frequency dataset on capital control actions, which allows us to more precisely capture the policy whose effectiveness is being assessed. This adds to the literature as most existing cross-country studies on the effectiveness of capital controls tend to use less precise (and annual) measures of

\footnotetext{
${ }^{3}$ Recent literature overviews suggest that capital flow measures have little effect on overall capital flows, although they may have an impact on the composition of flows (Magud et al., 2011). Effects of capital flow measures may vary markedly across the types of capital controls, with those on debt and equity flows being more effective in influencing capital flows than others (Binici et al., 2010). There is also evidence that controls may increase the maturity of inflows (De Gregorio et al., 2000).
} 
existence of capital controls across countries, which do not capture how policy is actually used for counter-cyclical macroeconomic management. Using data on policy actions also allows us to conduct the analysis using quarterly data, thus focusing on a horizon that is more relevant for policy-makers.

Second, we investigate the effectiveness of changes in capital controls in a model based on the monetary policy trilemma. ${ }^{4}$ The literature has identified several potential macroeconomic targets of using capital controls policy: the level or composition of capital flows, the level or volatility of exchange rate, and the level of monetary policy autonomy. These variables are related via the monetary policy trilemma. This trilemma, or the impossible trinity, states that it is impossible to simultaneously have a fixed exchange rate, an independent monetary policy and an open capital account. The trilemma assumes that a change in de-jure openness leads to an equivalent change in de-facto openness, and equates the two. This is where the scope for testing capital control effectiveness through the lens of the trilemma arises. In a panel VAR framework, we ask whether de-jure changes in a country's openness lead to changes in de-facto openness and therefore in the level of monetary policy autonomy and the volatility of the exchange rate. This approach also takes into account the endogeneity of capital controls, highlighted by the recent literature. ${ }^{5}$ Aizenman and Pasricha (2013), for example, find that countries actively modify capital controls to manage pressure of inflows, and Pasricha (2017) that capital controls policy systematically responds to both mercantilist and macroprudential concerns. While VARs have been commonly used in country-specific studies examining the impact of capital controls, we are among the first to use structural VARs in a panel setting, and, to our knowledge, the first to do this for spillover effects of capital controls. ${ }^{6}$

Third, we provide a comprehensive assessment of cross-country spillover effects of capital controls for both the pre- and the post-global financial crisis period, a topic on which there is currently little empirical evidence. The available evidence either pertains to post-crisis

\footnotetext{
${ }^{4}$ The empirical evidence on the effects of capital controls on the variables of the monetary policy trilemma is mixed. For instance, Klein and Shambaugh (2015) find that with pegged exchange rates, capital controls provide greater monetary autonomy only when they are long standing and extensive. Miniane and Rogers (2007) show that countries with more stringent capital controls were not more insulated from foreign monetary policy shocks. Hutchison, Pasricha and Singh (2013) find that even in a country with extensive capital controls, these controls were able to sustain a covered interest rate differential between onshore and offshore markets only in periods in which these controls were actively tightened. Further capital controls do not seem to have a clear effect on currency appreciation in most cases (Pandey et al., 2015; Jinjarak et al., 2013), with the exception of Chile in the 1990s (Edwards and Rigobon, 2009).

${ }^{5}$ Existing tests of the trilemma are based on testing whether the indices of (levels) of capital controls, monetary policy autonomy and exchange rate stability add to a constant (Aizenman, Chinn and Ito, 2010) or whether nominal interest rates in a country respond more to foreign interest rates in countries with more open capital accounts and less flexible exchange rates (Obstfeld, Shambaugh and Taylor, 2005) or testing comovements of asset prices with the global financial cycle (Rey, 2015).

${ }^{6}$ Saborowski et al. (2014) use panel VARs to assess the effectiveness of capital outflow restrictions in EMEs. Studies using country-specific VARs include Cardoso and Goldfajn (1998), De Gregorio et al. (2000) and Baba and Kokenyne (2011).
} 
years and the impact of one country's capital controls (Forbes et al., 2016; Lambert et al., 2011), one region (Chantapacdepong and Shim, 2015) or uses less precise measures of capital controls (Beirne and Friedrich, 2014; Giordani et al., 2017). We provide evidence that spillovers for the largest EMEs transcended regions and became stronger in the post-crisis environment of abundant global liquidity. We are among the first to provide evidence of policy spillovers, whereby countries respond to capital controls in the BRICS by changing their own capital controls.

On domestic effects, our main conclusion is that policy choices in EMEs during the 2000s were constrained by the monetary policy trilemma. Steps to dismantle capital account restrictions had a positive, though short-lived, impact on gross capital flows. As policy-makers gave priority to exchange rate stability, along with easing restrictions, there was a weakening of monetary policy autonomy. As both gross in- and outflows increased in response to easing of dejure capital account restrictions, there was no impact on net capital inflows. These findings are consistent with evidence in the literature that, in the past decade, EMEs have become more important as a source of capital in addition to being a recipient of capital, implying that the behavior of net capital flows depends more than in the past on resident flows. Our results thus suggest that resident flows warrant attention when analyzing the impact of capital controls.

As regards spillovers, our main finding is that the cross-border effects of capital flow policies are more important than generally thought. We find clear evidence that during the 2000s and early 2010s net inflow tightening measures in large countries had implications for other countries.

Our paper is structured as follows. After explaining our dataset on capital controls in Section 2, we discuss policy trends in capital control actions in Section 3. Section 4 discusses our empirical methodology. Our results for domestic and multilateral effects of capital controls are presented in Sections 5 and 6, respectively, and Section 7 concludes.

\section{Measuring capital controls ${ }^{7}$}

A cross-country empirical study of the effects of a certain policy hinges on the quality of the measurement of that policy. Measuring capital controls is a challenging task. The pre-global

${ }^{7}$ Further details about the data, including the dataset itself, are available at http://www.nber.org/data-appendix/w20822/. 
financial crisis literature used annual indices of the level of capital controls. ${ }^{8}$ These indices are better at capturing the extensive margin of controls (how many types of transactions are regulated) than the intensive margin (how the restrictions change over time for each type of transaction). In order to assess the effectiveness of controls, it is important to capture the intensive margin, i.e. how restrictive the controls are for each asset class and how they change over time. To give an analogy from measurement of monetary policy, the annual indices (e.g. Chinn-Ito) would count the number of monetary instruments a country has in operation (set at a non-zero value) in a given year, for example, interest rates, reserve requirements, asset purchases etc. It would not measure how these instruments change within the year (e.g.: interest rate increases or decreases).

The recent literature has tried to improve the measurement of the intensive margin by collecting data on changes in regulations (Pasricha, 2012; Forbes et al., 2015; Pandey et al., 2015). The benefit of this approach is that it allows us to precisely capture the nature of the policy intervention as well as the date of the intervention. However, the question of whether different policy actions are comparable over time and across countries continues to be as relevant for these datasets as for the older, less granular datasets of extensive margins. To return to the monetary policy analogy, the post-Brexit BoE monetary policy package included a decrease in the Official Bank Rate, a term lending scheme, a corporate bond buying program and an expansion of the government asset purchase program - should it count as one policy action or more ${ }^{9}$ This comparability of actions becomes more pressing for studies that seek to assess the impact of controls, rather than just the broad direction of policy.

\subsection{Constructing a comparable measure of capital control actions}

An improvement in the comparability of quantitative measures of policy actions (or policy changes) is essential if the aim is to precisely evaluate the impact of changes in controls, particularly in a cross-country context. Past studies have used different approaches to address this question. These approaches can broadly be grouped under two headings: the "splitting-theannouncements” approach and computing the tax equivalent of certain changes (which captures the economic size of the measure). In this article, we suggest a third approach, which combines

\footnotetext{
${ }^{8}$ See for example Chinn and Ito (2008), Schindler (2009) and Magud et al. (2011).

${ }^{9}$ Bank of England (2016) "Bank of England cuts Bank Rate to $0.25 \%$ and introduces a package of measures designed to provide additional monetary stimulus” Monetary Policy Summary, 4 August 2016.
} 
elements of both approaches: split the announcements and then weigh them according to their importance for the economy in question. This gives us a database that is closer to instrument level than other recent cross-country datasets on capital control actions.

The "splitting-the-announcements" approach aims to arrive at policy actions that are all relatively homogeneous and are expected to have a quantitatively similar impact on capital flows by decomposing a complex change in controls into its smaller, more homogenous subcomponents. Major policy announcements are split into smaller, more homogeneous ones. This approach is used by Pasricha (2012), Chantapacdepong and Shim (2015), Forbes et al. (2015) and Pandey et al. (2015), and necessarily involves the use of judgment. Forbes et al. (2015) drop all "very minor changes" and those that can be reasonably judged to have not been motivated by macroeconomic or macro-prudential management concerns, but rather by foreign policy or other domestic policy concerns. This approach still leaves a large number of changes of varying intensity.

Pasricha (2012) controls for the degree of restrictiveness of capital controls by classifying changes into eight different asset classes and decomposing them, within each asset class, into quantitative, monitoring and price-based measures. ${ }^{10}$ The asset classes include direct investment, capital and money market instruments, real estate transactions, etc. A policy change is a change in regulation related to one asset class. When a policy announcement has an impact on more than one asset classes, it is counted as many times as the number of asset classes it affects.

Pandey et al. (2015) go further in this direction by counting separately every regulatory instrument for controls on foreign borrowing in India. This yields a very detailed dataset with actions for each policy instrument. However, this methodology is not easily scalable for comparing changes across countries with different regulatory structures and regimes.

The second approach to improving the comparability of policy measures is to compute an implicit tax rate of the measures. This approach has been used in the literature on evaluating Chile’s capital controls (Valdés-Prieto and Soto, 1996; De Gregorio et al., 2000), and has recently been followed by Baba and Kokenyne (2011). ${ }^{11}$ A limitation of this approach, however,

\footnotetext{
${ }^{10}$ Price-based changes are those that seek to restrict or influence the price of transactions, such as, for example, taxes on inflows, reserve requirements (as a tax equivalent is easily computed for these) and ceilings on interest rate payable on foreign borrowings. Monitoring changes are those that require parties to submit information to the authorities on the transactions undertaken or to obtain approval in advance. Quantitative changes are the residual category and include limits on the size of transactions, minimum stay requirements on new inflows and all other restrictions that are neither price-based nor monitoring.

${ }^{11}$ Baba and Kokenyne (2011) count the non-price changes by AREAER category, but with 13 asset classes instead of the 8 used in Pasricha (2012).
} 
is that the effective tax rate can only be computed for certain kinds of policy instruments (e.g. unremunerated reserve requirements), which constitute a minority of the actions taken by EMEs. $^{12}$

In this article, we combine elements of both approaches. We follow Pasricha (2012) and count the policy changes separately, decomposing them into several categories. We subsequently weigh the changes by the share of the country's total international assets or liabilities that the measure is designed to influence. The weighting captures the degree of economic importance of the measure, in the same spirit as the tax equivalence.

A policy action in our dataset has a unique classification along six dimensions:

1. The direction of flows the measure regulates: Controls on resident liabilities (including on repayment of these liabilities) are called inflow controls and those on residents' external assets (including on the sale of these assets and repatriation of the funds) are called outflow controls;

2. The policy stance of the change: Easing or tightening or restrictions;

3. The type of CFM: Controls that discriminate based on residency are called capital controls and those that discriminate based on currency are called currencybased measures;

4. Whether the restriction is prudential or not;

5. The International Investment Position (IIP) category: Portfolio flows, FDI, Financial Derivatives, Other Investment;

6. The type of instrument: Price-based, quantitative or monitoring.

For the initial data on CCAs, we follow the more comprehensive approach used in Pasricha (2012) of supplementing information in the IMF's Annual Report on Exchange Arrangements and Exchange Restrictions (AREAER) with regulators' press releases/notifications, news sources, and other research papers. We have information on the date of announcement and when the policy action entered into force. ${ }^{13}$ We use the effective dates of the CCAs.

\footnotetext{
${ }^{12}$ Most quantitative or monitoring measures (e.g. changes in limits of total foreign portfolio investment) are not amenable to this transformation. Quantitative and monitoring capital control actions (CCAs) constitute about $80 \%$ of our database, while the price-based measures constitute the remaining $20 \%$.

${ }^{13}$ The effective date differs from the announcement date for $16 \%$ of the actions.
} 
Let $c_{i s j}$ be the $j^{\text {th }}$ policy action by country $i$ in period $s$, identified as above. A period can be a day, week, month or quarter. In this paper, $s$ denotes a quarter. A policy action can affect the asset side of a country's external balance sheet (outflow control) or the liability side (inflow control). That is, $c_{i s j}=\left\{c_{i s j}^{k}\right\}$ for $\mathrm{k}=\mathrm{A}, \mathrm{L}$.

Further, a policy action can be an easing $\left(e_{i s l}\right)$ or a tightening $\left(t_{i s l}\right)$ of restrictions.

If

$$
c_{i s j}=\left\{\begin{array}{c}
1 \text { if } j^{\text {th }} \text { action is easing } \\
-1 \text { if } j^{\text {th }} \text { action is tightening }
\end{array}\right.
$$

then,

$$
\begin{aligned}
e_{i s j} & = \begin{cases}1 & \text { if } c_{i s j}=1 \\
0 & \text { otherwise }\end{cases} \\
t_{i s j} & = \begin{cases}1 & \text { if } c_{i s j}=-1 \\
0 & \text { otherwise }\end{cases}
\end{aligned}
$$

$e_{i s j}=\left\{e_{i s j}^{k}\right\}$ and $t_{i s j}=\left\{t_{i s j}^{k}\right\}$, for $\mathrm{k}=\mathrm{A}, \mathrm{L}$.

Each policy action affects one of five types of investment (IIP categories): Portfolio Debt (PD), Portfolio Equity (PE), Foreign Direct Investment (FDI), Other Investment (OI) and Financial Derivatives (D). The weight assigned to a policy action $\left(w_{i s j}=\left\{w_{i s j}^{k}\right\}\right)$ is the last available value of the share of the IIP category it affects in the external balance sheet of the country. ${ }^{14}$ For example, if the policy action is a tax on foreigners' purchases of domestically issued bonds, the weight assigned to that action is:

$$
w_{i s j}^{L}=\frac{\text { Stock of Portfolio Debt Liabilities }_{i s-1}}{\text { Total External Liabilities }_{i s-1}}
$$

A change that influences all asset classes of inflows (or outflows) has the highest weight of 1 . Weighting the measures allows us to estimate more precisely the impact of the measures on the other macroeconomic variables as it controls for the size of the change. A change in capital

\footnotetext{
${ }^{14}$ IIP data is from the updated and extended dataset by Lane and Milesi-Ferretti (2007) and is available at an annual frequency. Therefore, for policy actions in the first-quarter of the year, the last available value is one-quarter lagged, whereas for the fourth quarter of every year, the weights use a 4-quarter lagged value. We lag the weights to control for endogeneity.
} 
controls that affects only a small portion of a country's foreign transactions is unlikely to lead to a large change in net capital inflows. A change that affects all the asset classes is likely to have a greater impact.

This approach allows us to obtain the most comparable dataset to date on capital control actions for a large number of economies and for a recent period, covering more than a decade. Our dataset contains changes in capital account regulations for 16 major EMEs between 2001 and 2012. It contains 782 CCAs at a daily frequency, which after weighting, sum to 228 CCAs (less than the number of unweighted changes as many measures do not affect all asset classes and thus receive a weight of less than 1).

To assess the impact of weighting scheme on the distribution of actions over time, we can compute the weighted and unweighted share of actions in period $s$ :

$$
\begin{array}{r}
W S_{i s}=\frac{\sum_{j=1}^{J_{S}} w_{i s j} e_{i s j}+\sum_{j=1}^{J_{s}} w_{i s j} t_{i s j}}{\sum_{s=1}^{S} \sum_{j=1}^{J_{s}} w_{i s j} e_{i s j}+\sum_{j=1}^{J_{S}} w_{i s j} t_{i s j}} \\
=\frac{\text { Number of weighted actions by country } i \text { in period } s}{\text { Total number of weighted actions by country } i} \\
S_{i s}=\frac{\sum_{j=1}^{S_{S}} e_{i s j}+\sum_{j=1}^{J_{S}} t_{i s j}}{\sum_{s=1}^{S} \sum_{j=1}^{J_{S}} e_{i s j}+\sum_{j=1}^{J_{S}} t_{i s j}}=\frac{\text { Number of actions by country } i \text { in period } s}{\text { Total number of actions by country } i}
\end{array}
$$

When $W S_{i s}>S_{i s}$, the average weight for policy actions in period $s$ is greater than the average weight across all periods. This means that the policy actions in period s (by country $i$ ) were relatively more broad-based, i.e. affected larger portions of the country's balance sheet than the average measure. Figure 1 plots the $W S_{s}$ and $S_{s}$ series (i.e. $W S_{i s}$ and $S_{i s}$ summed over all countries). The weighted and unweighted changes show a similar pattern over time. The number of modifications to capital controls reached a peak in the pre-global financial crisis years, 200708, when net capital inflows to these economies were surging, before declining sharply during the crisis. EMEs' reliance on capital control policies recovered after the crisis. The weighted series lies above the unweighted series in the years up to 2006, but below the unweighted series 
from 2006 to 2011. This suggests that the changes introduced up to 2006 were more broad-based than changes introduced after 2006. ${ }^{15}$

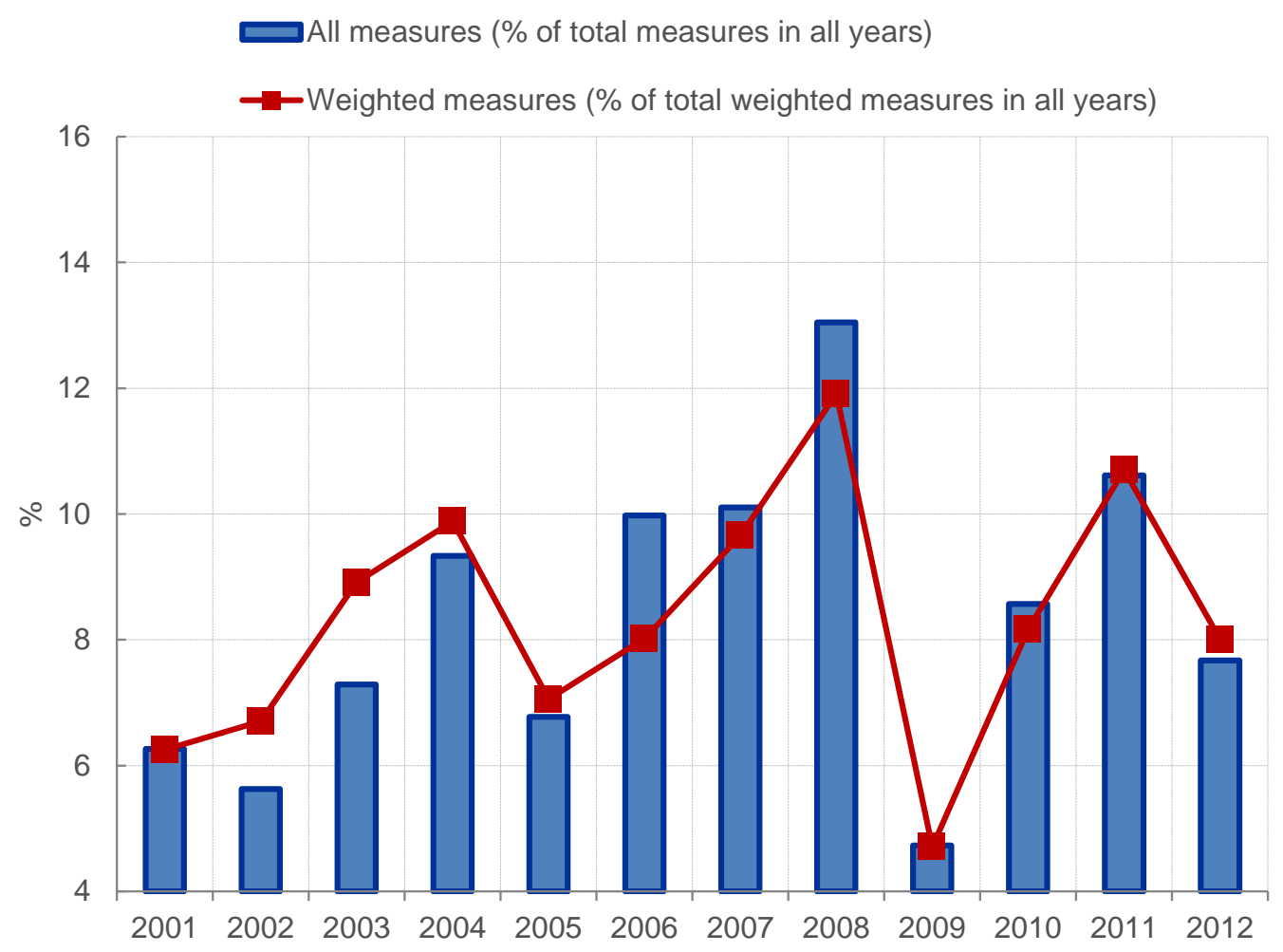

Figure 1. Weighted and un-weighted changes in capital controls follow similar patterns over time

\subsection{Economic classification of capital control actions}

For economic analysis, we need summary measures that capture the net direction of policy. We use three measures of the net direction and intensity of policy in our economic analysis:

$$
\begin{aligned}
& \text { WOpen }_{i s}=\sum_{j=1}^{J_{S}} w_{i s j} e_{i s j}-\sum_{j=1}^{J_{s}} w_{i s j} t_{i s j} \\
& W \text { II }_{i s}=\sum_{j=1}^{J_{S}} w_{i s j}^{L} t_{i s j}^{L}-\sum_{j=1}^{J_{S}} w_{i s j}^{L} e_{i s j}^{L} \\
& W N E O_{i s}=\sum_{j=1}^{J_{S}} w_{i s j}^{A} e_{i s j}^{A}-\sum_{j=1}^{J_{S}} w_{i s j}^{A} t_{i s j}^{A}
\end{aligned}
$$

\footnotetext{
${ }^{15}$ Note that some of the measures in the database are partial or full reversals of earlier measures. Brazil's tax on inflows, for example, was tightened and eased several times in the time period covered in our database.
} 
Where $J_{s}$ is the total number of actions in period $s$. Therefore, WOpen ${ }_{i s}$ is the (weighted) net increase in openness of country $i$ in period $s, W N T I_{i s}$ is the weighted net tightening of inflow controls and $W N E O_{i s}$ is the weighted net easing of outflow controls by country $i$ in period $s$. The variables $W N T I_{i s}$ and $W N E O_{\text {is }}$ thus target the net change in residents' liabilities to non-residents and the net change in residents' claims on non-residents, respectively.

These three measures of the net direction and intensity of policy are related in the following way:

$$
W_{O p e n}=W N E O_{i s}-W N T I_{i s}
$$

The change in capital account openness is the sum of the number of outflow easing actions and the number of inflow easing actions (all measures are weighted). In other words, the change in openness increases with measures that ease inflow or outflow restrictions and it declines with measures that tighten inflow or outflow restrictions.

For domestic effects, the main capital control variable is the change in capital account openness $\left(W_{0 p e n} n_{i s}\right)$. We choose this capital control variable for our specification for domestic effects because the opening (or closing) of the capital account represents one of the corners of the trilemma. According to the trilemma, a more open capital account could increase exchange rate stability but only if a country gives up monetary policy autonomy. Or, greater capital account openness could come with an increase in monetary policy autonomy, but in that case the exchange rate would be less stable.

Given that the policy debate on spillovers has focused on inflow controls by some EMEs re-directing global liquidity towards other emerging markets, we use foreign net inflow tightening as our main capital control variable in our assessment of multilateral effects. The choice of foreign net inflow tightening for assessing spillover effects is also based on the empirical evidence that flows from EMEs to other EMEs are still rather small (Karolyi et al., 2015). Finally, it is also possible to group the measures into whether they would encourage or discourage net capital inflows (NKI), i.e. the difference between inflows and outflows. It allows us to see a visual correspondence between the direction of policy and the intended outcome variable, net capital inflows. Since both outflow easing and inflow tightening would tend to 
reduce the pressure of net capital inflows, we define net NKI restricting measures (WNNKIR $\left.R_{i s}\right)$ as a summary measure of the degree of restrictiveness towards net capital inflows:

$$
W N N K I R_{i s}=W N T I_{i s}+W N E O_{i s}
$$

To sum up, the change in openness is a summary measure of the policy stance towards capital account liberalization and can be directly linked to the trilemma, while net NKI restricting measures capture the degree to which policies aim at discouraging net capital inflows.

\section{Recent trends in capital controls}

Capital control actions in EMEs since 2000 have largely mirrored fluctuations in net capital inflows into these economies, as illustrated by the evolution of net NKI restricting measures over time (Figure 2). EME policy turned sharply restrictive during the years immediately preceding the global financial crisis following a surge in net capital inflows. The number of net NKI restricting measures turned negative during 2008Q4-2009Q1 as the events during the global financial crisis engendered EME attempts to reverse the sudden stop. In 2010, however, the number of NKI restricting measures picked up sharply again, following a recovery in capital inflows into EMEs. This pick-up in capital inflows reflected the relatively strong growth performance of EMEs and accommodative monetary policies in advanced economies.

With the reversal in capital inflows in mid-2011, EME policy switched to policies that encouraged net capital inflows. Although the reversal in capital inflows in 2011 proved temporary, and EMEs saw relatively large net capital inflows during 2012, the policy stance continued to be welcoming toward net inflows. 


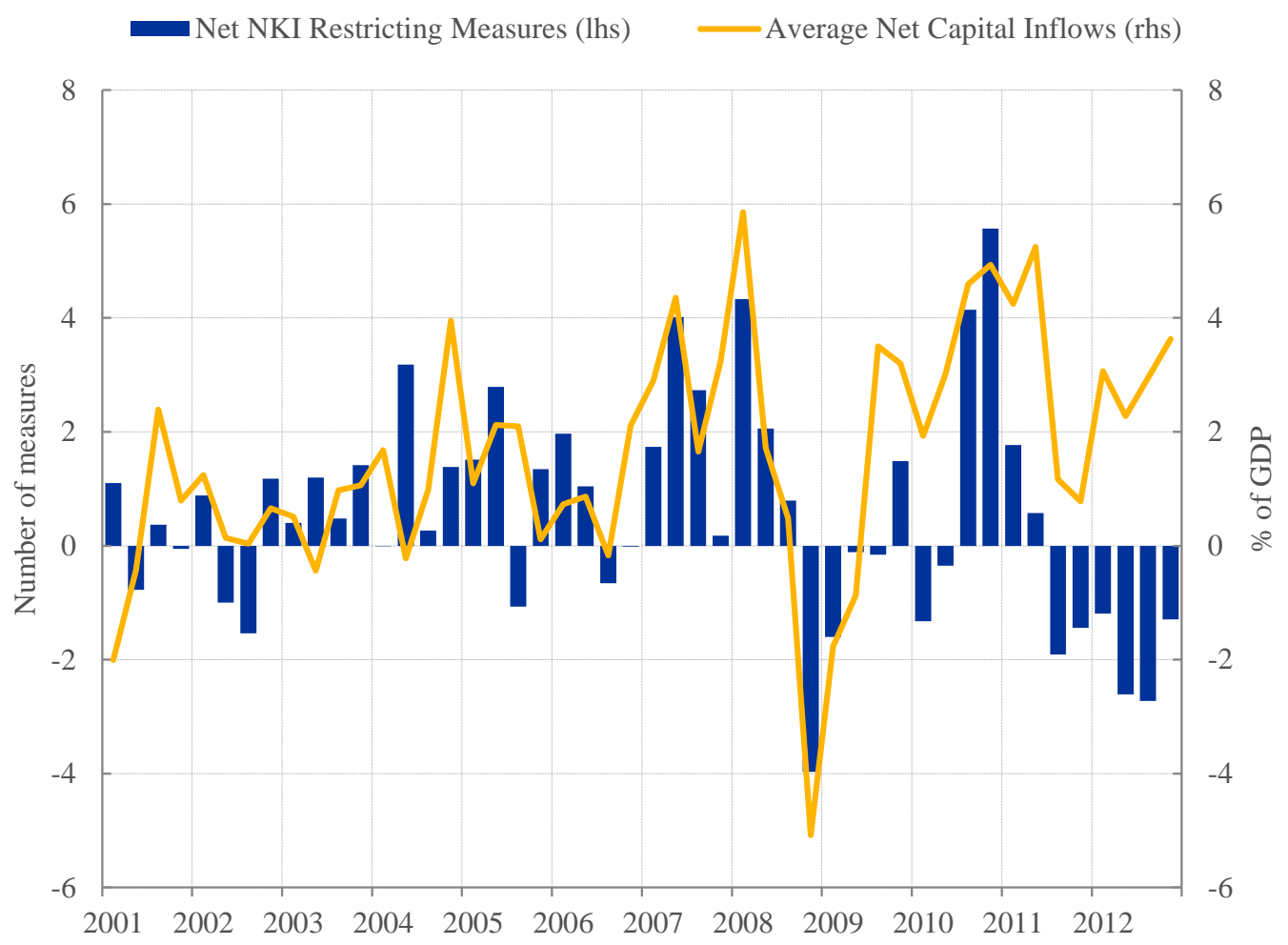

Note: Net private capital inflows exclude government and monetary authority transactions from "other" inflows and outflows. Net private capital inflows are therefore the sum of FDI, net portfolio inflows, net "private" other inflows and net derivative inflows, and are calculated on a quarterly basis as averages over 16 EMEs using seasonally adjusted data. Net NKI restricting measures is the difference between NKI reducing capital control actions (inflow tightening and outflow easing) and NKI increasing actions (inflow easing and outflow tightening). All measures are weighted and refer to unannounced CCAs. The number of measures represent totals for 16 EMEs.

Figure 2. Net NKI restricting capital control measures exhibit a cyclical pattern

Although capital control policies have mostly been aimed at restricting net capital inflows since the early 2000s, countries took measures that increased the openness of the capital account most of the time, as NKI restricting measures were partly implemented via net outflow easing (Figure 3a). The sample period was characterized by a net relaxation trend of both inflow and outflow controls, resulting in an increase in capital account openness. However, inflow liberalization slowed or reversed, and outflow liberalization accelerated during periods of high net capital inflows. Inflow liberalizations were stepped up during periods of inflow weakness or sudden stops, including the global financial crisis in 2008 (Figure 3b). Inflow tightening actions, by contrast, were concentrated in periods of greater net capital inflows, including the periods preceding the global financial crisis (2004-05 and 2007-08) and the period immediately 
following the global financial crisis (2010-11), when capital flows to emerging markets recovered sharply. These were also periods when EMEs accelerated the liberalization of outflow controls. $^{16}$

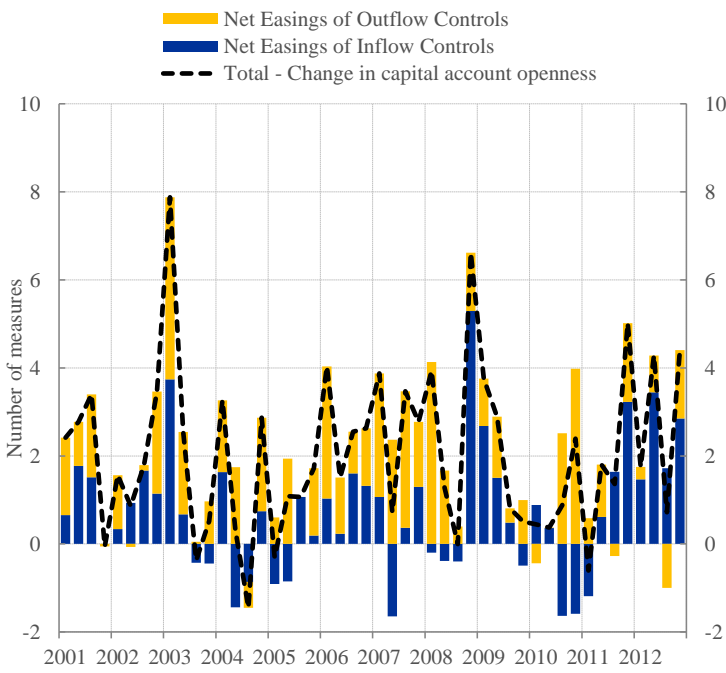

(a)

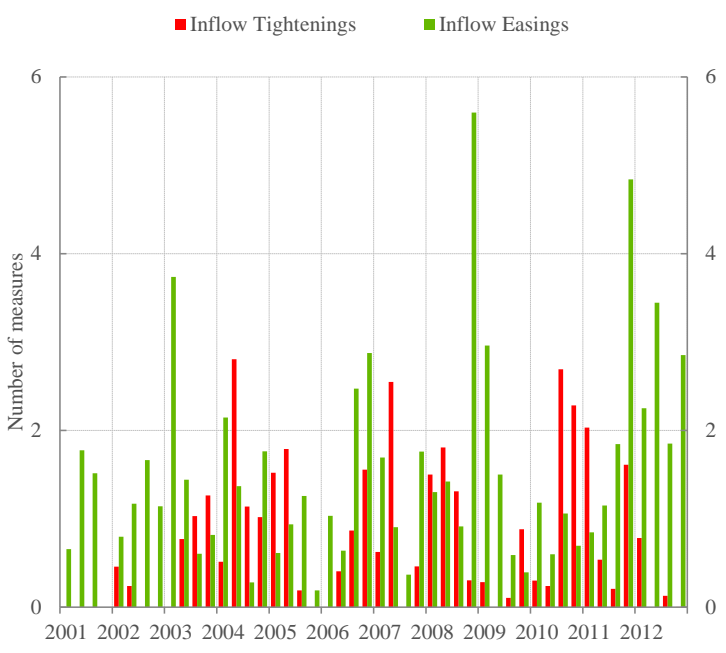

(b)

Note: The change in capital account openness in panel (a) is the sum of the number of net easing measures of inflow and outflow controls. The number of net tightening inflow measures in panel (b) is the difference between the number of inflow tightenings and the number of inflow easings. The numbers are totals for 16 EMEs. All measures are weighted.

Figure 3. EMEs liberalized both inflow and outflow restrictions most of the time

Policy changes were sometimes of a conflicting nature from a point of view of managing net capital inflows. For example, in 2006Q2-2007Q2, when emerging economies faced large net capital inflows and overheating pressures, countries took a significant number of inflow easing measures alongside adjustments that tightened inflow controls. ${ }^{17}$ This nuances the widespread view that policy-makers in EMEs only tighten controls in the face of a surge in inflows to manage macroeconomic and financial stability risks, while they only ease them in case of a sudden stop.

\footnotetext{
${ }^{16}$ Note that there are very few tightening measures on the outflow side in the sample, because of which net easing of outflow controls largely reflects easing of outflow controls.

${ }^{17}$ The easing measures taken during this period applied to both hot inflows and FDI-related inflows.
} 


\section{Data and empirical strategy}

Capital control policies may have an impact on a range of variables, as well as be driven by these variables. Therefore, we estimate a system of equations for capital control actions, capital flows, a measure of monetary policy autonomy and exchange rate volatility, treating all these variables as endogenous. These variables are interdependent per the impossible trinity or monetary policy trilemma, which asserts that a country can maintain only two of three policy objectives: a fixed exchange rate, open capital markets and domestic monetary policy autonomy.

In our sample, we have 16 countries, for the period 2001Q1 to 2012Q4. Table 2 has the list of countries. We want to capture a large and representative share of the group of emerging economies in our sample. We therefore base our sample on the countries in the MSCI Emerging Markets Index plus Argentina (which is in G20), but we exclude the EU countries in the index (Czech Republic, Greece Hungary and Poland whose capital controls are constrained by EU rules), Egypt and Taiwan (data constraints) as well as Greece, Qatar and the United Arab Emirates (not yet part of the MSCI index when our dataset was compiled). For the empirical analysis, we also drop observations for Argentina and Turkey prior to 2004Q1 and for Russia prior to 2002Q1, to exclude their crisis periods.

\subsection{Baseline model I: Effectiveness of domestic capital control changes}

Our baseline model is a panel VAR (PVAR) in which all variables of interest are treated as endogenous, while controlling for several exogenous push factors. Our model is represented by a system of equations, which can be written in reduced-form as:

$$
y_{i, t}=a_{0}+A_{1} y_{i, t-1}+\ldots+A_{p} y_{i, t-p}+B_{1} x_{i, t-1}+\ldots+B_{q} x_{i, t-q}+d_{i}+\varepsilon_{i, t}
$$

where $y_{t}$ is a $(k \times 1)$ vector of endogenous variables for country $i, x_{t}$ is a $(k \times 1)$ vector of exogenous variables common to all countries, $\varepsilon_{i, t}$ is a $(k \times 1)$ vector of reduced-form residuals, $A_{J}(J=1, \ldots, p)$ and $B_{l}(l=1, \ldots, q)$ are $(k \times k)$ matrices of coefficients for the endogenous and exogenous variables, respectively, and $d_{i}$ is a vector of country-specific intercepts. The inclusion

of country fixed effects aims at controlling for time-invariant omitted factors (e.g. institutional quality) that may affect the dynamics of the system across countries. 
The baseline model includes the following endogenous variables at quarterly frequency: a capital control variable capturing the change in capital account openness (WOpen $n_{i s}$ ), the absolute value of short-term interest rate differential vis-à-vis the United States, the volatility of the spot exchange rate vis-à-vis the US dollar and gross capital inflows and outflows. All endogenous variables, except capital control variables, are included in our model in their first difference. The reason for differencing our endogenous variables is that, in contrast to many other studies using capital control data (e.g. Schindler/Fernandez et al. or Chinn-Ito indices), our capital control variables are defined as changes to capital account regulations. For consistency reasons, we also express our other endogenous variables in terms of (quarter-on-quarter) changes. ${ }^{18}$

We use an overall measure of capital account openness because it is difficult to disentangle the impact of separate inflow and outflow measures given that both types of measures tend to happen simultaneously. In our dataset, a country adjusts both inflow and outflow restrictions in the same quarter in $48 \%$ of the quarters in which it changes a capital control. Further, there are important differences across countries. For example, bilateral correlations between different types of measures show that in Brazil, India, Korea and Thailand, policy-makers tend to ease inflows and outflow restrictions in the same quarter (both measures imply a liberalization of the capital account). In Peru, by contrast, there is a relatively high positive correlation between net outflow easing and inflow tightening (both measures reduce net capital inflows).

One concern with the panel specification may be the extent to which our capital controls dataset captures cross-country variation as well as time-series variation in policy. As we discussed in Section 2, weighting the capital control changes in our dataset by their importance to the country's balance sheet adds to the cross-country comparability of policy actions. However, we also investigate the implications of using alternative indices for capital controls that rely more on cross-sectional information, but are of a lower frequency compared with our dataset (see Section 5.2).

Regarding the other variables, we use the absolute value of the interest rate differential as an indicator of monetary policy autonomy. The ability to maintain a differential between

\footnotetext{
${ }^{18}$ This is consistent with Forbes et al. (2016) which uses similar data on Brazil's capital controls actions and assesses their impact on the changes in portfolio allocations. Baba and Kokenyne (2011) estimate country-specific VARs using levels of macro-financial variables, but they cumulate the capital controls policy actions to get a level measure of capital controls.
} 
domestic and foreign interest rates (irrespective of whether it is positive or negative) serves as a proxy for the ability to maintain a difference between desired and actual capital flows and therefore to set domestic interest rate independently from the foreign rate. As a measure of exchange rate volatility, we use the within-quarter standard deviation of the (log of the) bilateral exchange rate vis-à-vis the US dollar. It is computed using daily data. Finally, our capital flow variables are both gross inflows and outflows because we want to assess their responses separately. All capital flow measures are seasonally adjusted (using the Census X12 method) and expressed as a share of GDP. In the baseline model, we do not differentiate between FDI and non-FDI changes given that this distinction does not play a role in the trilemma, but we do perform robustness checks with capital flows and capital controls excluding FDI.

In addition, we include a set of exogenous variables to control for factors that may have an impact on the endogenous variables in our model, but that are not affected by the interdependence of the trilemma. These include three global variables: the short-term US interest rate (federal funds rate, replaced by the shadow rate in 2009 to capture the presence of the zerolower bound for interest rates and the impact of non-conventional monetary policies), the crude oil price and real GDP growth in the US. In addition, we add as an exogenous variable the lagged year-over-year growth rate of domestic bank credit, following the evidence in Pasricha (2017) that capital control policies systematically responded to bank credit. Finally, we include a dummy for the global financial crisis. ${ }^{19}$

In our baseline model, the number of lags $p$ of the endogenous variables is two, while the number of lags $q$ of the exogenous variables is one in order to limit the number of parameters to estimate. ${ }^{20}$ We use the Stata program developed by Abrigo and Love (2015), and estimate the baseline model using GMM, allowing for country heterogeneity in the levels of the variables by introducing fixed effects and using a forward mean-differencing procedure to ensure that the orthogonality between transformed variables and lagged regressors is preserved. As stressed by Abrigo and Love (2015), the GMM estimator suffers from weak instrument problems when the endogenous variables have a unit root. We run unit-root tests and find no unit roots in the capital control variables and the other endogenous variables, which are already first-differenced.

\footnotetext{
${ }^{19}$ As we are interested in the effectiveness of capital controls in "normal" times, we use a crisis dummy to account for the impact of crisis episodes on the variables in our model. This dummy takes the value one during the global financial crisis (the observations from 2008Q3 until and including 2009Q2) for all countries in the sample.

${ }^{20}$ We test up to four lag lengths for endogenous variables and select two quarters based on standard lag length selection criteria (AIC, SBC/BIC and $\mathrm{HQ}$ ).
} 
To recover the structural shocks from the VAR innovations, we adopt the recursive Choleski decomposition identification. This decomposition provides a minimum set of assumptions that can be used to identify the structural shocks of interest, namely the shocks to the capital control variables. Our baseline ordering is as follows: 1) capital control measure; 2) the absolute interest rate differential; 3) capital flows; and 4) the volatility of the spot exchange rate vis-à-vis the US dollar. The Choleski ordering assumes that the variables that come earlier in the ordering affect the following variables contemporaneously (as well as with a lag), while the variables that come later affect the previous variables only with a lag. Our main identifying assumption is that policy-makers do not react to changes in the other variables within the same quarter as the decision-making process takes time. We opt for a relatively agnostic identification scheme, without imposing, for example, restrictions on the impulse responses, as the direction of the responses to shocks is the focus of our analysis. As we are agnostic about the directions and the speed of the responses of the other variables, the structural interpretation of our model is partial and we focus only on the impact of shocks to the capital control variable.

To sharpen the identification, we only use unannounced capital control changes, thereby excluding changes that were announced in a quarter prior to their implementation date (except if the announcement is in the last five days of the previous quarter). This ensures that most of the impact of the capital controls is felt in the current or the next quarters and will be measured in our estimates. Moreover, to check the appropriateness of the shock identification (that capital controls do not respond contemporaneously to capital flows), we also conduct a multi-step exercise to isolate the unexpected component of the capital control changes. We first predict capital control policy in each EME using the predicted values of the given EME's contemporaneous capital flows and contemporaneous change in the exchange rate against the US dollar. To generate the predicted values, other EMEs’ contemporaneous net capital inflows and exchange rate changes are used as instruments, respectively. We then use the residuals of these regressions to derive the exogenous component in capital control decisions. Finally, we test the robustness of our results to several alternative model specifications.

Our expectations of the results are based on the predictions of the trilemma. If the trilemma applies, a more open capital account will increase gross flows, and can change a country's policy configuration in three ways. First, greater capital account openness would inevitably reduce monetary policy autonomy if policy-makers prefer a more stable exchange 
rate. Second, a more open capital account could also give a country more monetary policy autonomy, but then policy-makers would have to accept a less stable exchange rate. A third possibility is that a more open capital account could lead to a limited reduction in both monetary policy autonomy and exchange rate stability. ${ }^{21}$ A combination of more monetary policy autonomy, a more stable exchange rate as well as a more open capital account would in any case be inconsistent with the trilemma. Our analysis can thus be an empirical test of whether the trilemma applies, as well as an assessment of the effectiveness of changes in capital controls (impact on gross flows).

\subsection{Baseline model II: Spillover effects of capital control changes}

To assess the strength of cross-country spillover effects, we use a modified version of the baseline model by imposing more structure on the interrelations between the endogenous variables. More specifically, we assume that the BRICS countries (Brazil, Russia, India, China and South-Africa) are affected by spillovers of capital control actions by any of the other BRICS, but that spillovers to other EMEs arise only from the actions of the regional BRICS country. For example, our hypothesis is that the most likely spillovers from capital control actions by India are to the other Asian countries in the sample (e.g. Thailand or Malaysia) or to the other BRICS (i.e. other large emerging economies) as these represent closer substitutes to India than smaller countries in other regions (e.g. Argentina or Peru). We thus construct a count variable that, for each of the BRICS, is the sum of the number of weighted policy changes in all the other BRICS in a given quarter. For each of the other countries in the sample (i.e. the non-BRICS), the variable is the sum of the number of weighted actions by the regional BRICS country (i.e. Brazil for Latin America, China and India for Asia, Russia for emerging Europe - i.e. only Turkey in our sample) in a given quarter. Given that capital flows from EMEs to other EMEs are still relatively unimportant as EME residents mainly invest in advanced economies, an easing of outflow restrictions in one EME is not expected to lead to noticeably larger gross inflows to another EMEs. Therefore, we focus only on spillovers generated by changes in inflow controls. The spillovers from these controls are expected to come from changes in the behavior of

\footnotetext{
${ }^{21}$ The possibility of choosing a middle configuration, rather than a corner of the trilemma triangle, is explored in the literature that deals with the rounding of the corners of the trilemma. For example, Aizenman, Chinn and Ito (2010, 2016) and Klein and Shambaugh (2015) explore this empirically, while Farhi and Werning (2012) and Schmitt-Grohe and Uribe (2012) explore theoretically the possibility that temporary capital controls allow greater freedom for domestic macroeconomic management.
} 
advanced economy investors, as they adjust the composition of their portfolios between different emerging economy assets, or from the behavior of EME residents, who decide whether to invest abroad (in advanced economies) or domestically, and in which assets.

We model the impact of spillovers of capital control actions using a structural near-VAR approach, which differs from the standard fully symmetric structural VAR in the sense that it constrains specific shocks to affect only some variables in the system. ${ }^{22}$ This allows us to restrict the coefficients for changes in capital controls in other countries to zero, implying that the domestic variables in the system do not have an impact on capital control decisions by policymakers in other countries. Apart from these additional restrictions, compared to the model described in Section 4.1, we replace the volatility of the spot exchange rate vis-à-vis the US dollar with its quarter-on-quarter percentage change. Moreover, given that the focus of the spillover analysis is not on the trilemma, but rather on the impact of inflow tightening measures on other countries, we use those measures (i.e. $W N T I_{i s}$ as defined in Section 2) in this part of the analysis rather than an overall indicator of capital account openness. All the other features of the model (exogenous variables, number of lags) are kept unchanged.

Since the explanatory variables in each equation of a structural near-VAR are not identical, the system of equations constitutes a Seemingly Unrelated Regressions (SUR) model, in which the error terms are assumed to be correlated across the equations. ${ }^{23}$ To estimate the SUR model, we use a common variant of Markov Chain Monte Carlo methods, the Gibbs sampler, which is a standard tool for posterior simulation. The results are obtained from 25000 replications from the Gibbs sampler, with 5000 burn-in replications discarded and 20000 replications retained. ${ }^{24}$

If spillover effects are present, we expect that a tightening of inflows in BRICS would increase capital inflows to other countries, lead to an appreciation of their currencies and reduce their domestic interest rates relative to foreign interest rates.

\section{Results: Domestic effects of capital controls}

\footnotetext{
${ }^{22}$ Near-VAR models have been employed for example by Agenor and Hoffmaister (1998) and Olson et al. (2012), and panel near-VARs by Peersman (2004).

${ }^{23}$ The SUR model was first proposed by Zellner (1962).

${ }^{24}$ We choose standard uninformative priors. More specifically, we impose flat priors on the coefficients and standard Jeffrey's prior on the covariance matrix. For more details on the Gibbs sampler, see Koop (2003) and Doan (2009).
} 
In this section, we investigate whether changes in capital controls have an impact on gross capital flows, monetary policy autonomy and exchange rate stability in line with the predictions of the trilemma. To make the impulse response functions comparable across different samples, the impulses are standardized to a one unit shock. The responses are expressed in the unit of each respective variable.

\subsection{Results of the baseline model}

Figure 4 shows the impulse response functions to a shock in capital account openness using our baseline model based on the full sample. These impulse responses show that, following a one unit shock to openness (i.e. an increase in capital account openness by one weighted measure), both the absolute differential between the short-term domestic and the US interest rate and the volatility of the exchange rate vis-à-vis the US dollar decline, i.e. more openness leads to greater exchange rate stability and less monetary policy autonomy. These impacts are statistically significant and occur quickly after the shock, but they are short-lived. For exchange rates the entire impact occurs within one quarter, while for interest rates the impact lasts up to three quarters. The longer impact on interest rates suggests that the loss in monetary policy autonomy lasts longer than the gain in exchange rate stability. In both cases, the impacts peak in the same quarter during which the shock takes place.

Policy-makers in EMEs thus gave up some of their monetary policy autonomy during the 2000s. After taking steps to dismantle capital controls, they probably gave greater priority to exchange rate stability rather than monetary policy autonomy. This trade-off between capital mobility, exchange rate stability and monetary policy autonomy is consistent with the predictions of the trilemma. Within the triangle of the trilemma, the policy preference chosen by EMEs implies a movement away from the corner of the triangle that represents monetary policy autonomy towards more capital mobility and a more stable exchange rate.

Using the coherence between the domestic and the foreign interest rate as a proxy for monetary policy autonomy is a standard approach in the literature (Obstfeld, Shambaugh and Taylor, 2005). One could, however, debate whether a reduction in absolute interest differential reflects a loss of monetary policy autonomy for countries where exchange rate pass-through to inflation is high and inflation expectations are not well anchored. In these situations, in response

to an exogenous shock stemming from a tightening of US monetary policy, a decline in the 
absolute interest differential vis-à-vis the US may well be in line with the domestic inflation mandate (Vegh, 2017 and Tapia, 2017).

In this context, we note three points: first, we are testing the impact of a shock to capital controls, a domestic policy variable, on other domestic policy variables as well as foreign exchange volatility and capital flows, holding other things, including exogenous variables, constant. Second, in a scenario of a tightening of US monetary policy, while an optimal monetary policy response in the absence of capital controls may be a tightening of domestic monetary policy (i.e. a pro-cyclical monetary policy, which leaves constant or reduces the absolute interest differential with the US), capital controls are used precisely to provide space for monetary policy to maintain a countercyclical rather than a pro-cyclical stance. The implementation of capital controls may, in the short run, provide the monetary space needed to adjust the domestic interest rate, mitigating the exposure to greater real exchange rate instability associated with short-term capital flows that may react to US monetary policy innovations. Finally, we note that the trilemma constrains the functioning of most monetary regimes, including the various versions of inflation targeting. We do not have the detailed data required to test the unresolved issues with the trilemma. For example, we are unable to control for the degree to which inflation expectations are anchored. We rely on our identification strategy as a reduced-form approach that captures some of these issues. Testing these issues in more detail will require more data and is left for future research.

The changes in trilemma configuration occur through changes in gross flows. Figure 4 shows that an increase in capital account openness leads to a statistically significant increase in both gross capital inflows and outflows. Similar to the other variables in the model, these impacts are quick and short-lived as they die out after one quarter. An increase in capital account openness is thus associated with an increase in capital flows. While both in- and outflows increase, our model simulations using net instead of gross flows show that the effect on net capital inflows is not significant. This result is in line with findings in the literature that suggest that capital controls affect gross rather than net capital flows (Ahmed and Zlate, 2014). These findings also confirm a stylized fact from the empirical literature that shows that capital account liberalization has historically generated large gross capital in- and outflows, but the direction of net flows has depended on many factors (Bayoumi and Ohnsorge, 2013). These factors may include the (relative) business cycle, growth expectations and whether capital account 
liberalization is embedded in a broader reform package that strengthens the attractiveness of the country as an investment destination. Finally, our results also support the theoretical work by Bartolini and Drazen (1997), who show that capital account liberalization can provide signals of future government policies, implying that a removal of controls on outflows can lead to an increase in inflows.
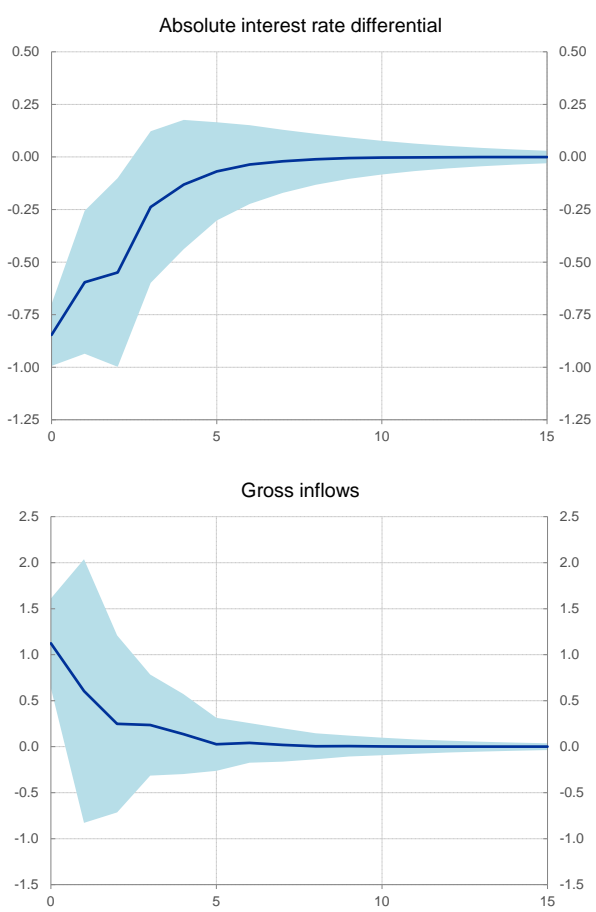
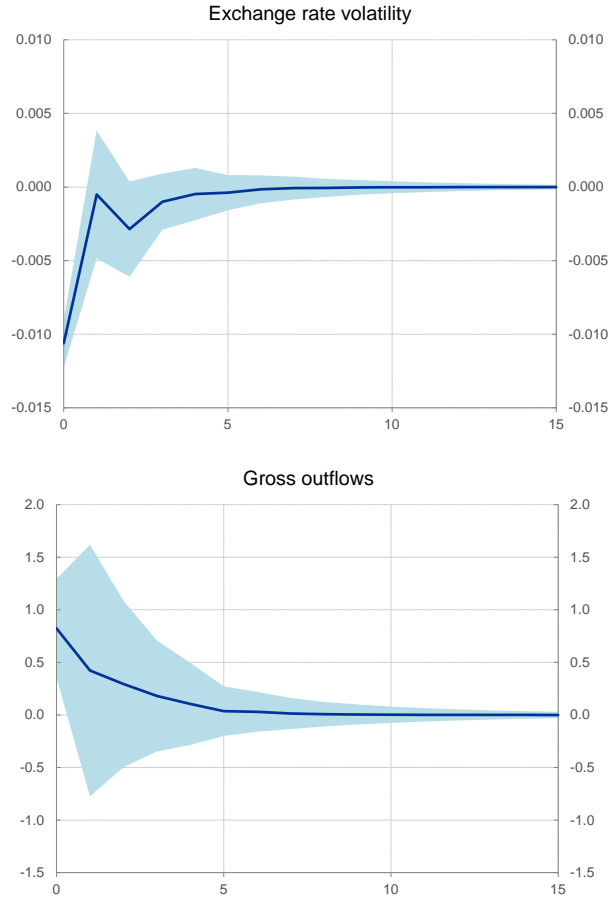

Note: The lines show the impact of a one unit (i.e. one measure) increase in capital account openness, using weighted capital control changes. The shaded areas denote the $90 \%$ confidence intervals. The responses are expressed in the unit of each variable (exchange rate volatility: q-o-q changes in the standard deviation of the daily changes in the exchange rate vis-à-vis the US dollar during each quarter; 3-month money market interest rate differential: q-o-q change in the absolute value of the differential, in percentage points; capital flows: q-o-q changes in seasonally-adjusted flows expressed as a percentage of GDP).

Figure 4. Domestic impact of an increase in capital account openness - baseline

The observation that capital-control policy matters mostly for gross flows and not for their net movement, but nevertheless affects exchange rates and monetary policy autonomy reflects the possibility that prices can adjust without a change in underlying flows (Rey, 2017; Froot and Ramodarai, 2005). Price changes may take place, for example, due to shifts in expectations, changes in order flows (Gyntelberg et al., 2018; Fan and Lyons, 2003) or alterations in the composition of flows due to portfolio rebalancing (Alpanda and Kabaca, 2015). 
In fact, Alpanda and Kabaca (2015) also show that the portfolio rebalancing can lead to spillovers in the form of shifts in gross flows and risky longer term rates, without necessarily having an impact on net flows.

\subsection{Time series vs. cross-sectional variation in capital controls}

It is important to note that the above results are based on both the time-series and the cross-section dimension of the data. Our dataset captures the time dimension of the data with a high degree of precision, which is crucial given that the effects of capital control changes tend to be short-lived. The cross-sectional comparability of capital control actions is captured mainly via the country-fixed effects and, to a lesser extent, by the splitting of announcements and weighting of the changes based on a country's international balance sheet position. The identification of the shocks therefore not only relies on the time dimension of the data, but also on the relative importance of a capital control change in comparison with other countries.

In order to investigate whether the cross-sectional variation in capital controls can be better exploited, we re-run our model using the Chinn-Ito (Chinn-Ito, 2008) and Fernandez et al., 2016 indices for capital controls. As before, all variables are included in their first difference. ${ }^{25}$ These indices capture the cross-country variation in the level of financial openness, but they are weaker on the time dimension given their construction methodology and annual frequency. The main difference between both indices is that the Chinn-Ito index is a broader measure of financial openness, covering also restrictions to the current account of the balance of payments and on the foreign exchange market, while the Fernandez et al. (2016) dataset is narrower, focusing only on capital transactions, but has more information on intensity of restrictions, with disaggregated data on capital controls on various asset classes. ${ }^{26}$ To the extent that countries remove or add restrictions on particular asset classes over time, the Fernandez et al. (2016) index would capture more of the time variation in the data than Chinn-Ito index.

The results using the Chinn-Ito do not confirm the trade-offs of the trilemma (Figure 5). An increase in capital account openness reduces gross capital flows, while increasing the interest rate differential and exchange rate volatility. The responses using the Fernandez et al. (2016)

\footnotetext{
${ }^{25}$ To capture the cross-sectional variation in the Chinn-Ito and Fernandez et al. (2016) indices in an alternative manner, we also perform the analysis using the levels of these indices (each in a separate regression) together with our own index and examine the impact of a shock to the latter (while dropping the country-fixed effects). In that case, the effects on most variables are not significant, with the exception of a downward impact on exchange rate volatility.

${ }^{26}$ The Fernandez et al. (2016) index also incorporates authors’ judgement on the degree of restrictiveness of capital controls in each asset class.
} 
index are in the same direction as those using our dataset, but for gross flows they are not significant (Figure 6). This suggests that annual indices that primarily capture the level of capital account restrictiveness may not be optimal for assessing the impact of capital control changes. Higher frequency data are able to pick up the short-term tightening and easing of policies more accurately, and therefore better reflect the cyclical variations in the intensity of restrictions.
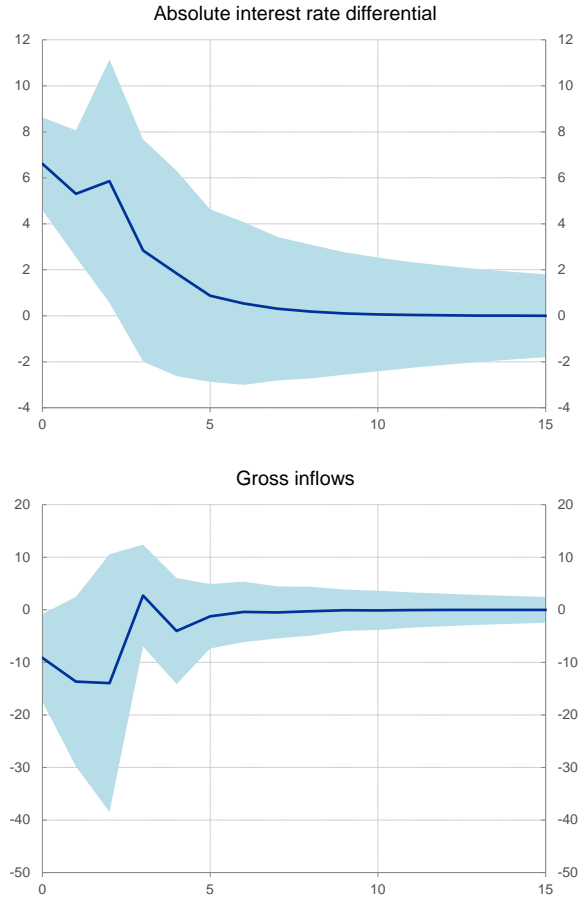
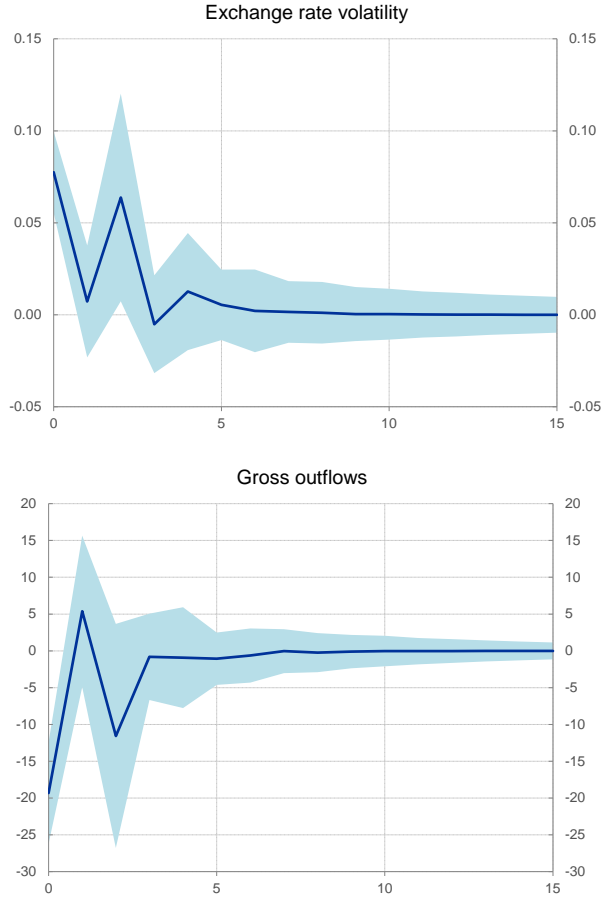

Note: The lines show the impact of a one unit (i.e. one measure) increase in capital account openness, using the Chinn-Ito index. The shaded areas denote the $90 \%$ confidence intervals. The responses are expressed in the unit of each variable (exchange rate volatility: q-o-q changes in the standard deviation of the daily changes in the exchange rate vis-à-vis the US dollar during each quarter; 3-month money market interest rate differential: q-o-q change in the absolute value of the differential, in percentage points; capital flows: q-o-q changes in seasonally-adjusted flows expressed as a percentage of GDP).

Figure 5. Domestic impact of an increase in capital account openness (using the Chinn-Ito index) 


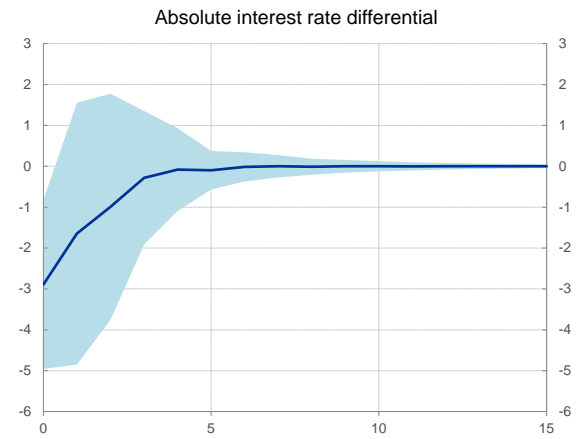

Gross inflows

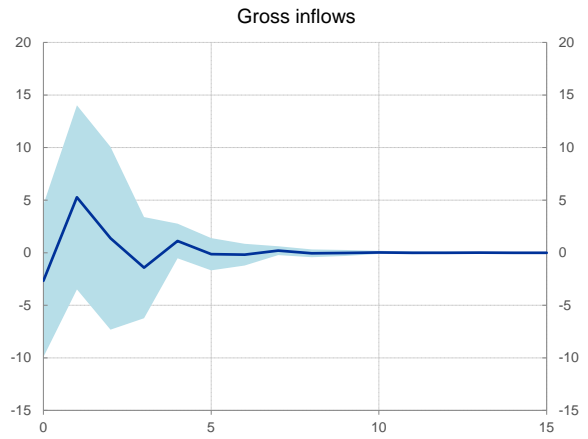

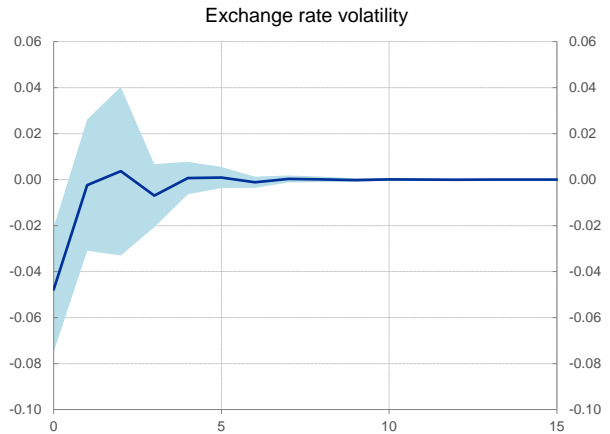

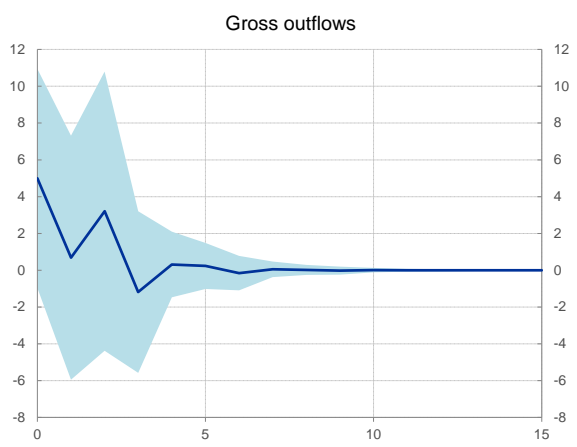

Note: The lines show the impact of a one unit (i.e. one measure) increase in capital account openness, using the Fernandez et al. index. The shaded areas denote the 90\% confidence intervals. The responses are expressed in the unit of each variable (exchange rate volatility: q-o-q changes in the standard deviation of the daily changes in the exchange rate vis-à-vis the US dollar during each quarter; 3-month money market interest rate differential: q-o-q change in the absolute value of the differential, in percentage points; capital flows: q-o-q changes in seasonally-adjusted flows expressed as a percentage of GDP).

Figure 6. Domestic impact of an increase in capital account openness (using the Fernandez et al. (2016) index)

\subsection{Shock identification based on first-stage regressions for capital controls}

The impulse responses can only be given a structural interpretation if we capture the truly exogenous component of the shock. One potential concern in this regard is that decisions on capital controls may be taken in response to changes in economic or financial conditions, for example, to respond to capital inflow pressures or because of macroprudential concerns (Aizenman and Pasricha, 2013; Forbes et al., 2015; Pasricha, 2017).

To isolate the component of the capital control change that is not endogenous, we follow a three-step approach. First, to account for contemporaneous capital inflow pressures, we instrument net capital inflows (spot exchange rate change vis-à-vis the US dollar) in quarter $t$ using the contemporaneous and the one-quarter lagged net capital inflows (spot exchange rate 
change vis-à-vis the US dollar) in other EMEs. Second, we use the predicted net capital inflows and spot exchange rate changes in a regression that explains capital control changes. Finally, we use residuals from the second stage regressions on capital controls, to derive the part of capital control actions that is not predicted by contemporaneous net capital inflows and exchange rate change, as the endogenous variable in the structural PVAR.

Table 1 reports the results of the second step of our approach. The estimates show that the capital control actions in our dataset do not seem to be taken in response to capital inflow pressures, providing some evidence of their ability to capture the exogenous component of a policy change. ${ }^{27}$

\begin{tabular}{lcc}
\hline \hline & Capital account openness & Net inflow tightening \\
\hline Predicted net capital inflows & -0.003 & 0.014 \\
& $(0.018)$ & $(0.011)$ \\
Predicted spot exchange rate change & 1.245 & -1.202 \\
& $(0.819)$ & $(0.858)$ \\
\hline Observations & 711 & 711 \\
$\mathrm{R}^{2}$ & 0.007 & 0.022 \\
\hline Notes: Predicted net capital inflows and spot exchange rate changes are measured contemporaneously. Robust \\
standard errors in brackets. Each regression includes a constant, which is not reported above. * significant at the \\
10\% level.
\end{tabular}

Table 1. First-stage regressions to model capital control policies

When we use the residual of this first-stage regression as a measure of exogenous capital control actions, the results confirm, not surprisingly, our earlier findings. The size of the impacts is similar to those in the baseline model and the effects are still statistically significant. In fact, the confidence intervals of the impulse responses are narrower than in the baseline model. The smaller size of the impacts and the narrower confidence bands suggest that this multi-step approach captures the exogenous shock to capital controls somewhat better than in the baseline model without changing the key result.

\footnotetext{
${ }^{27}$ The rather low $\mathrm{R}^{2}$ of the models may also reflect the presence of a non-linear relationship and/or the large number of quarters when there is no change in policy.
} 

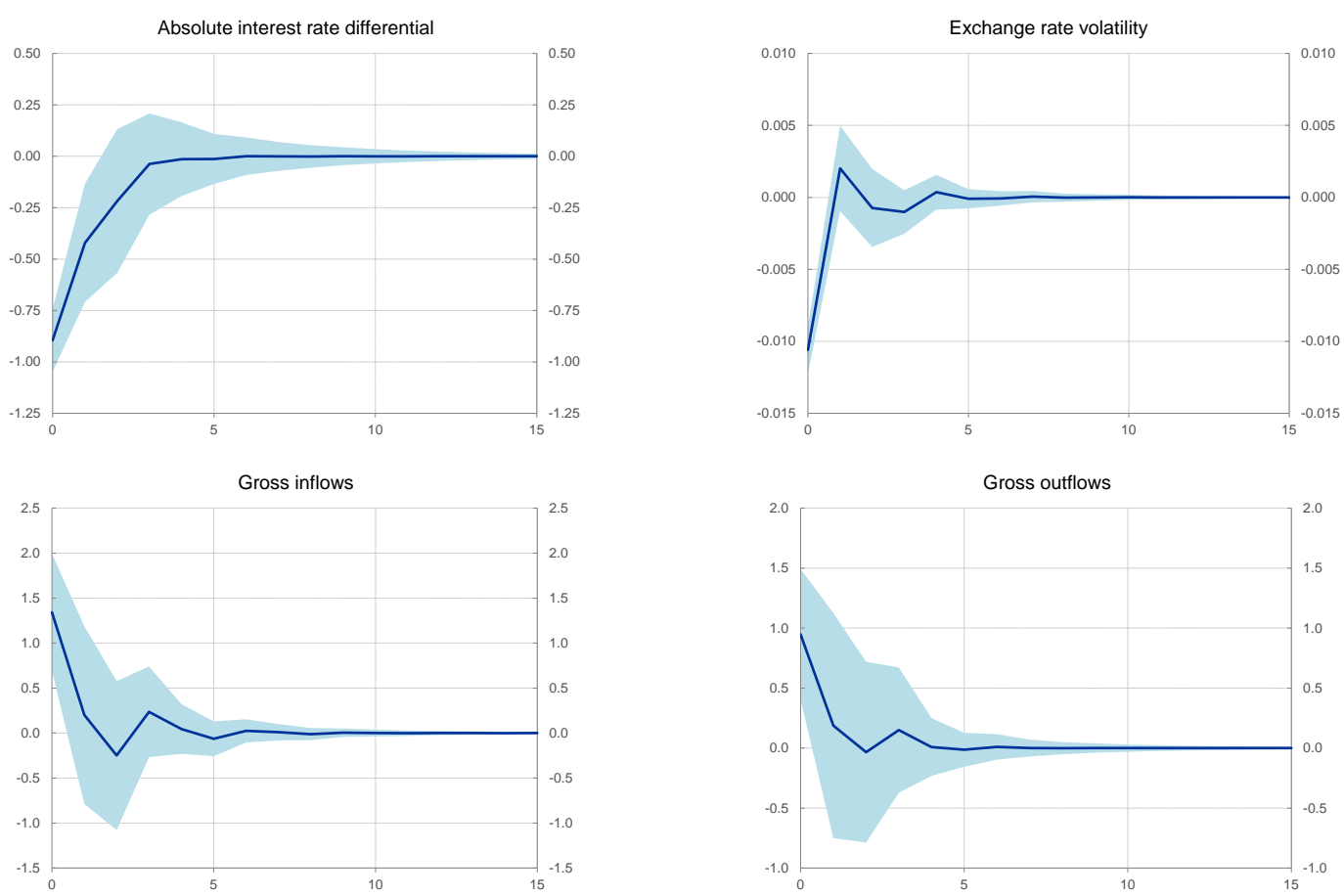

Note: The lines show the impact of a one unit (i.e. one measure) increase in capital account openness, using the residual of the first-stage regression modelling capital control policies. The shaded areas denote the $90 \%$ confidence intervals. The responses are expressed in the unit of each variable (exchange rate volatility: q-o-q changes in the standard deviation of the daily changes in the exchange rate vis-à-vis the US dollar during each quarter; 3-month money market interest rate differential: q-o-q change in the absolute value of the differential, in percentage points; capital flows: q-o-q changes in seasonally-adjusted flows expressed as a percentage of GDP).

Figure 7. Domestic impact of an increase in capital account openness (using the residual of the first-stage regression modelling capital control policies)

\subsection{The role of foreign exchange reserves}

Recent literature has argued that reserves are a fourth dimension in the trilemma, allowing countries to circumvent the constraints on policy choices posed by the trilemma. Countries may accumulate international reserves in order to achieve some target combination of exchange rate stability, monetary policy autonomy and capital account openness (Aizenman et al., 2010). More specifically, the accumulation of large foreign reserve holdings by some EMEs during the 2000s might have allowed countries to mitigate the loss in monetary policy autonomy while stabilizing their exchange rate, as their capital accounts became more open. Our results suggest that this is the case, although the gains in terms of a more favorable trilemma configuration are small (Figure 8). As before, the impulse responses show that an easing of capital account regulations is followed by an increase in exchange rate stability and a loss in monetary policy autonomy, but this loss is somewhat smaller than in the model without reserves. 
At the same time, a more open capital account results in a short-lived decline in foreign reserves. In other words, policy-makers use foreign reserves to partly absorb the loss in monetary policy autonomy following an increase in openness. These results suggest that accumulating large foreign exchange reserves may be attractive for countries to soften the constraints of the trilemma, even though the gains achieved seemed to have been small. This could be an explanation for the strong increase in foreign reserves by EMEs during the 2000s.
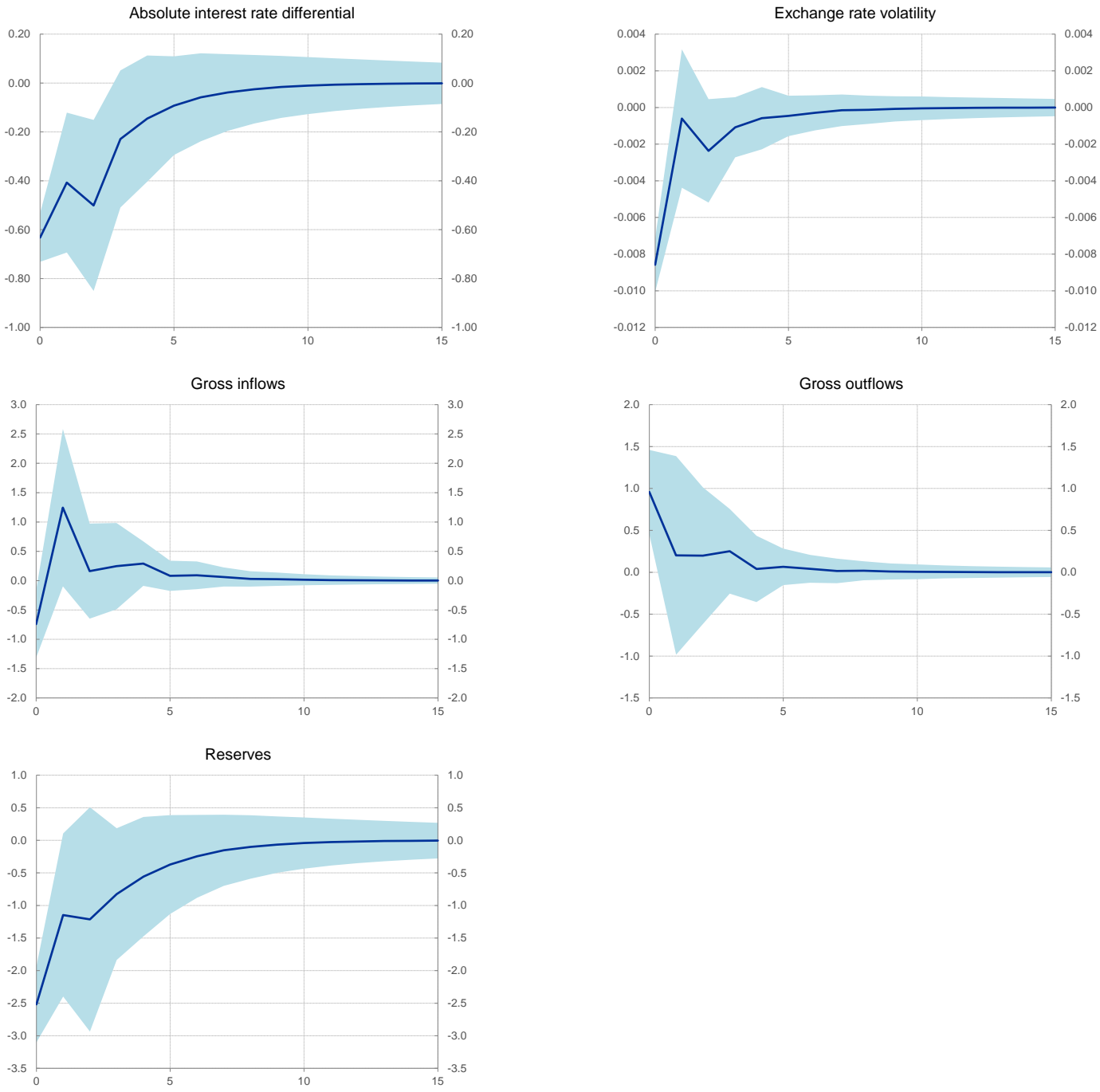

Note: The lines show the impact of a one unit (i.e. one measure) increase in capital account openness, using weighted capital control changes. The shaded areas denote the $90 \%$ confidence intervals. The responses are expressed in the unit of each variable (exchange rate volatility: q-o-q changes in the standard deviation of the daily changes in the exchange rate vis-à-vis the US dollar during each quarter; 3-month money market interest rate differential: q-o-q change in the absolute value of the differential, in percentage points; capital flows and reserves: q-o-q changes in seasonally-adjusted flows expressed as a percentage of GDP).

Figure 8. The role of reserves 


\subsection{The impact of inflow and outflow measures}

To investigate whether the impact of capital control changes depends on the type of measure, we replace capital account openness with separate inflow and outflow measures. However, while interpreting these results, it is important to bear in mind the caveat mentioned in Section 4.1 that inflow and outflow measures are often used in the same quarter, and their individual impact may be hard to disentangle. We use net inflow tightening given that EME policy-makers during the 2000s often aimed at curbing strong capital inflows. ${ }^{28}$ A net tightening of inflow controls has an upward impact on the interest rate differential and increases exchange rate volatility, while both inflows and outflows of capital decline (Figure 9). Similar to the model with the capital account openness measure, all impacts are significant but short-lived, though the impact on monetary policy autonomy lasts longer than that on exchange rate volatility. These results suggest that a tightening of inflow controls, implying a less open capital account, resulted in more monetary policy autonomy and a less stable exchange rate. The latter impact, however, faded more quickly than the effect on monetary policy autonomy. To the extent that exchange rate volatility temporarily increases, one may consider the inflow tightening to be only partly effective in achieving its objectives. The results are consistent with existing literature: Edwards and Rigobon (2009) find that a tightening of Chile's capital controls led to an increase in unconditional volatility of the exchange rate and attribute this to greater market segmentation of the foreign exchange market. Further, the literature on order flow has shown that foreign investors' transactions in the stock market can have a different impact on exchange rates than their transactions in bond markets (Gyntelberg et al., 2018), and that transactions by different types of foreign investors also affect exchange rate (and therefore its volatility) differently (Fan and Lyons, 2003). By generating order flow from different types of investors and in different markets, capital controls could increase exchange rate volatility, at least temporarily.

\footnotetext{
${ }^{28}$ Note that in this section, capital control variables for inflows are defined as net tightening. The expected signs of impulse responses are the opposite of those for baseline model with net openness as the capital control variable. This facilitates interpretation, but has no impact on the size of the estimated IRFs or their significance.
} 

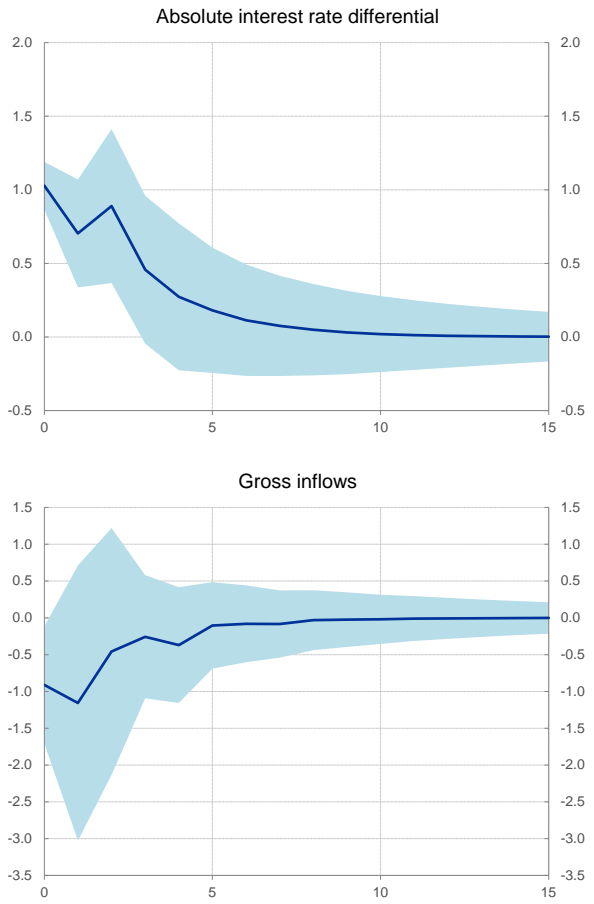
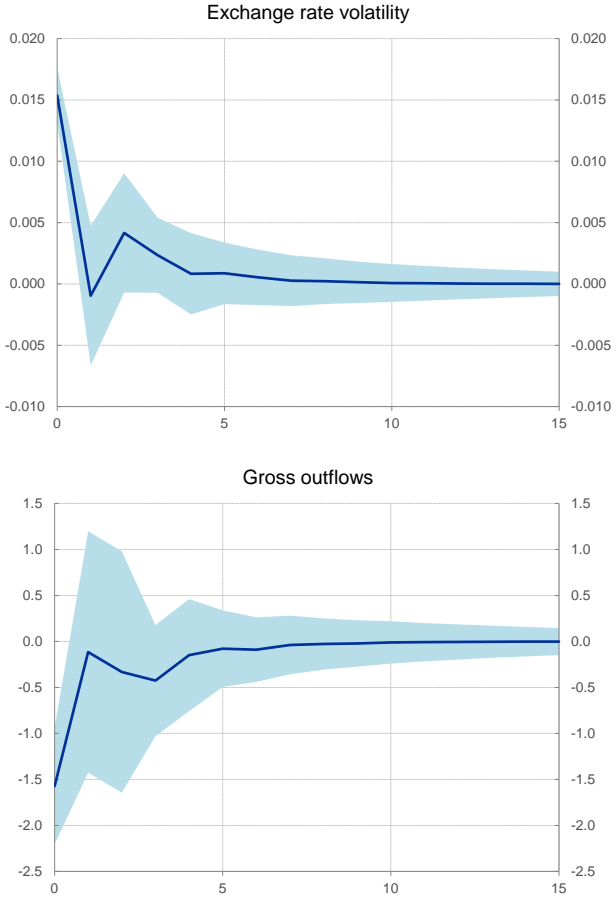

Note: The lines show the impact of a one unit (i.e. one measure) increase in net inflow tightening, using weighted capital control changes. The shaded areas denote the $90 \%$ confidence intervals. This model also includes net outflow tightening as endogenous variable. The responses are expressed in the unit of each variable (exchange rate volatility: q-o-q changes in the standard deviation of the daily changes in the exchange rate vis-à-vis the US dollar during each quarter; 3-month money market interest rate differential: q-o-q change in the absolute value of the differential, in percentage points; capital flows: q-o-q changes in seasonally-adjusted flows expressed as a percentage of GDP).

Figure 9. Impact of a net inflow tightening

These results also show that efforts to curb capital inflows by tightening inflow restrictions were effective in curbing gross inflows, although their impact was only short-lived. Moreover, this impact was offset by a greater drop in gross outflows given that residents invested less abroad as domestic interest rates increased, implying that net capital inflows were unaffected or even increased marginally. These findings underline again the importance of looking at gross rather than net flows when analyzing the effects of capital controls. While much of the existing literature emphasizes the opportunities for evasion of marginal inflow controls as overall capital account openness increases, our results suggest that the impact of controls on residents' outflows is another channel through which emerging economies may see their efforts to manage net capital inflows frustrated. 

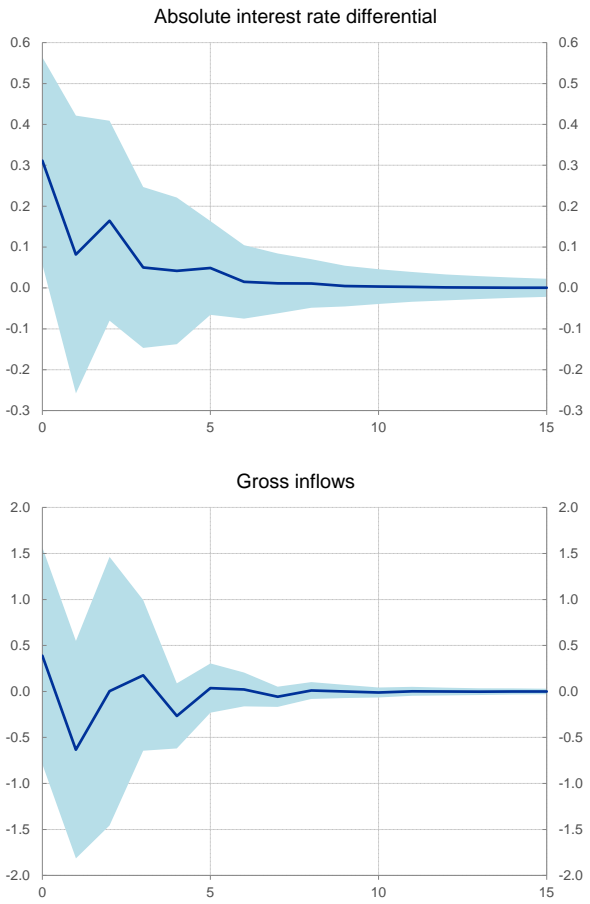
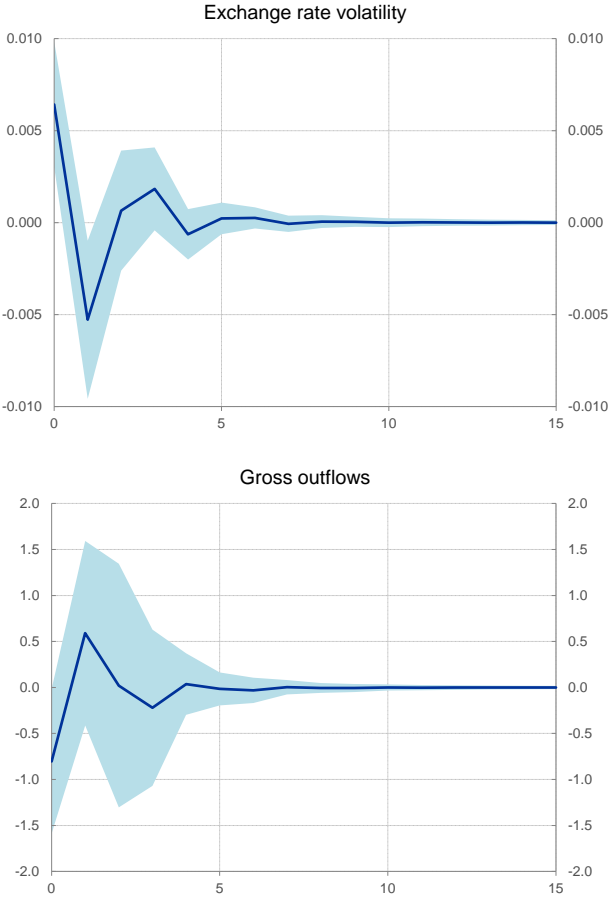

Note: The lines show the impact of a one unit (i.e. one measure) increase in net outflow easing, using weighted capital control changes. The shaded areas denote the $90 \%$ confidence intervals. This model also includes net inflow easing as endogenous variable. The responses are expressed in the unit of each variable (exchange rate volatility: q-o-q changes in the standard deviation of the daily changes in the exchange rate vis-à-vis the US dollar during each quarter; 3-month money market interest rate differential: q-o-q change in the absolute value of the differential, in percentage points; capital flows: q-o-q changes in seasonallyadjusted flows expressed as a percentage of GDP).

Figure 10. Impact of a net outflow easing

Turning to the outflow side, a net easing of outflow controls increases monetary policy autonomy, but this comes at the cost of higher exchange rate volatility on impact (Figure 10). Exchange rate volatility declines in the next quarter while the impact on monetary policy autonomy is no longer significant. This is consistent with the trilemma findings for more openness in the baseline model: more of one trilemma variable (monetary policy autonomy) is traded off against less of the other (exchange rate stability).

Looking at the impact of net outflow easing on capital flows, Figure 10 shows that there is no clear impact on capital flows. A possible explanation why outflow easing did not have a significant impact on capital flows may stem from the fact that most outflow easing measures were undertaken in an environment of strong domestic economic and financial conditions. This suggests that outflow restrictions in those circumstances may not have been binding in many 
countries given the relatively abundant domestic investment opportunities in EMEs during the sample period.

\subsection{Summarizing the results for domestic effects}

Our results show that policy choices in EMEs during the 2000s were shaped by the constraints of the monetary policy trilemma. Changes to capital controls had a short-term impact on gross capital flows, but they did not allow countries to escape the policy constraints posed by the trilemma. Steps to dismantle capital account restrictions during the 2000s increased gross flows and seem to have weakened monetary policy autonomy of EMEs as policy-makers gave priority to exchange rate stability. However, net capital inflows did not change as changes in gross inflows were offset by changes in gross outflows. The trend towards capital account liberalization has made it easier for residents in EMEs to adjust their investment activities abroad in response to changes in capital controls. Our results are consistent with evidence in the literature that in the past decade EMEs have become more important as a source of capital in addition to being a recipient of capital, implying that the behavior of net capital flows depends more than in the past on resident flows than on non-resident flows (Karolyi et al., 2013; Forbes and Warnock, 2012).

The above findings on the policy trade-offs of the trilemma are robust to several modifications of our model. The robustness checks we perform include alternative capital control variables (those excluding FDI), alternative indicators for monetary policy autonomy using the Aizenman-Chinn-Ito index of monetary policy autonomy (Aizenman et al., 2010) and the nominal short-term interest rate differential instead of its absolute value, alternative Choleski orderings for the interest rate differential, the exchange rate, international reserves and capital flows, and a different number of lags for the endogenous variables (i.e. three instead of two quarters).

We also test the sensitivity of the results controlling for additional exogenous variables, specifically the VIX index and global liquidity (world M2/GDP). We find a consistent direction of impulse responses. However, the confidence intervals surrounding the impulse responses of the variables of interest, particularly for gross flows, are wider than in the baseline model. This may be due to the fact that these additional global variables are highly correlated with the US federal funds rate, as well as with the changes in capital account openness. 


\section{Results: Multilateral effects of capital controls}

Capital flow measures in EMEs could spill over to other economies by increasing or decreasing flows to countries with similar characteristics or in the same region, or have an impact on the other variables of the trilemma in those countries. Understanding the multilateral implications of capital control policies is relevant for several reasons. First, capital control actions by some capital-receiving countries may deflect capital towards other recipient countries that do not impose such controls and exacerbate their overheating pressures or domestic financial imbalances. Second, capital controls may have the effect of hampering or postponing external adjustment, for example when inflow controls are used to sustain an undervalued currency.

Empirical evidence of cross-country spillovers using detailed data on capital control changes remains scant. ${ }^{29}$ In this section, we use the structural VAR model described in Section 4.2 to analyze these externalities for CCAs in the BRICS. We first look at the evidence for the full sample in a panel setting and then we analyze interactions between specific countries in country-by-country VARs.

\subsection{Results of the baseline model}

Figure 11 shows impulse responses using our model with spillover effects for net inflow tightening $\left(W N T I_{i s}\right.$ as defined in Secion 2), based on the full sample. We use net inflow tightening measures instead of the overall measure of openness $W O p e n_{i s}$ as the focus of this analysis is not on the trilemma, but on those policies that generate cross-border spillovers. As discussed in Section 4.2, we expect cross-border spillovers to be caused mainly by inflow rather than outflow measures. This expectation is in line with our findings comparing the domestic impact of inflow and outflow measures on capital flows discussed in Section 5.5. In this model, spillover effects are defined as spillovers from any of the BRICS countries to the other BRICS or from any of the BRICS to the other countries in the same region. We find clear evidence that a tightening of inflow restrictions creates significant, temporary spillovers to other countries.

\footnotetext{
${ }^{29}$ A recent event study by Forbes et al. (2016) suggests that capital flow measures in Brazil spilled over to other countries. Giordani et al. (2017) find that capital controls during 1995-2009 deflected capital flows to other countries with similar economic characteristics, but they do not find evidence of a policy response in those countries. While Forbes et al. use data on capital control actions, Giordani et al. use annual data on levels of capital controls.
} 
In more detail, net inflow tightening measures in BRICS spill over to other EMEs by initially increasing (gross) capital inflows into those countries and by placing upward pressure on their currencies (Figure 11). This coincides with a temporary downward impact on short-term interest rates, as authorities may respond by lowering interest rates (to make capital inflows less attractive), although that impact is not statistically significant. These effects occur immediately, i.e. in the same quarter during which the shock takes place. To curb those capital inflows and counter the upward pressure on the currency, the domestic authorities react by tightening inflow restrictions (outflow restrictions are also eased, but that impact is not significant). This policy reaction is effective and leads to a reversal of the capital inflow reaction in the following quarter, which turns into a decline that broadly offsets the initial upward impact on capital inflows. This decline in capital inflows is comparable with our findings for the domestic impact of a tightening of inflow restrictions discussed in Section $5 .{ }^{30}$ As capital inflows fall, the appreciation of the currency peters out (but is not reversed) and domestic interest rates are increased vis-à-vis the US. Domestic interest rates may reflect a policy response to stem capital inflow reversals. The resulting higher rates of return on domestic investments induce residents to invest more domestically and gross outflows decline in the second and third quarter after the shock in foreign capital controls.

\footnotetext{
${ }^{30}$ Note that as the models in Section 5 and here are different, any comparison between the two models should be qualitative only. Moreover, the impact on capital inflows shown in Figure 11 is not the result of the tightening of domestic inflow restrictions only, but reflects the combination of foreign and domestic capital control shocks.
} 

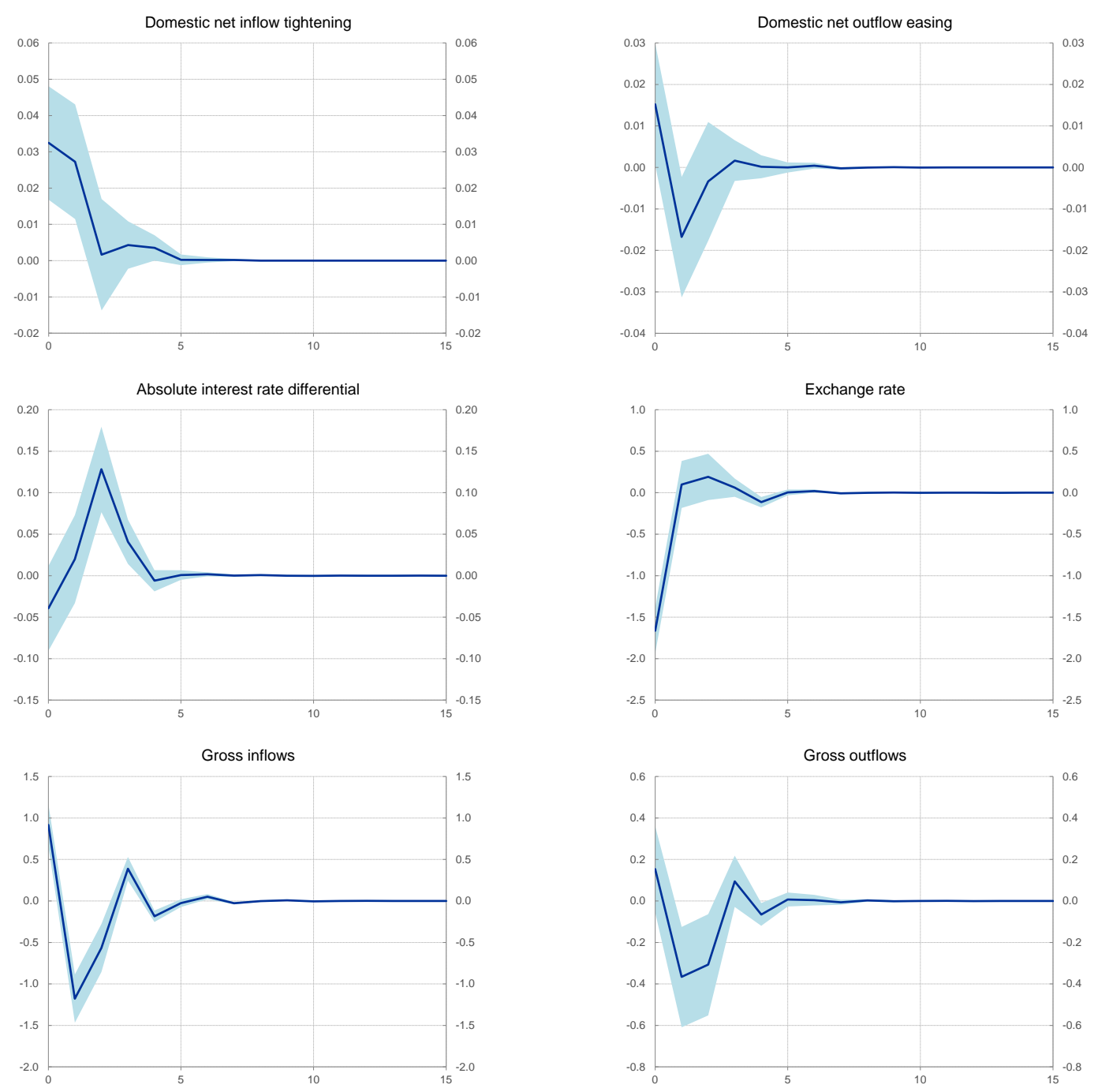

Note: The lines show the impact of a one unit (i.e. one measure) increase in foreign net inflow tightening, using weighted capital control changes. The shaded areas denote the 16 and 84 percentiles. The responses are expressed in the unit of each variable (exchange rate: q-o-q percentage changes; 3-month money market interest rate differential: q-o-q change in the absolute value of the differential, in percentage points; capital flows: q-o-q changes in seasonally-adjusted flows expressed as a percentage of GDP).

Figure 11. Inflow and outflow measures - Spillover effects: Impulse responses in the baseline model

Our finding that capital controls entail spillovers to policy in other countries is supported by theory, but we are among the first to find empirical evidence supporting such spillovers. Giordani et al. (2017) present a model in which an increase in capital controls causes a similar policy response in another country. The increase in capital inflows into the recipient country as a result of a tightening of capital controls in another country exacerbates the negative externality 
and triggers a policy reaction in the recipient country to tighten its own capital controls. However, Giordani et al. (2017) do not find empirical support for this preposition. The most likely explanation seems to be the fact that their dataset for capital controls (based on the Fernandez et al. (2016) index) does not capture the intensive margin of capital controls and is thus less suited for this type of analysis (see Section 5.2).

\subsection{Have spillovers changed over time? Pre-vs. post-global financial crisis}

Given the increased size and volatility of capital flows to EMEs (IMF, 2011b), the question comes up whether the importance of spillover effects has increased over time. To investigate this, we split the sample into two parts: the years before the start of the global financial crisis (2001Q1-2008Q2) and the years after the crisis (2009Q3-2012Q4). Figure 12, which reports the results for the pre-crisis period, shows more mixed results for the significance of spillover effects than Figure 13, which covers the post-crisis period.

The results in Figure 12 show that, before the crisis, net inflow tightening measures in BRICS led to an initial appreciation of other countries’ currencies and increase in their shortterm interest rates. Policy-makers in other EMEs reacted by easing outflow restrictions, which was followed by a reversal in the initial impact on exchange rates and interest rates. Later, inflow restrictions were also tightened and capital flows did not exhibit a statistically significant reaction. However, the size of most responses, in particular for the exchange rate, is several times smaller than those in the full sample and there is no significant impact on capital flows before the crisis. Overall, the spillover effects of capital control changes before the crisis seems to have been rather muted.

After the global financial crisis the evidence for spillovers becomes substantially stronger. Figure 13 shows that a net tightening of foreign inflow controls leads to an immediate appreciation of other countries' currencies and increases their gross capital inflows. In the following quarters, these impacts come to an end as domestic inflow controls are tightened, gross capital inflows decline and the short-term interest rate differential increases. The increase in the

domestic interest rate (relative to US rates) induces domestic residents to invest less abroad, which is illustrated by a (short-lived) decline in gross capital outflows. 

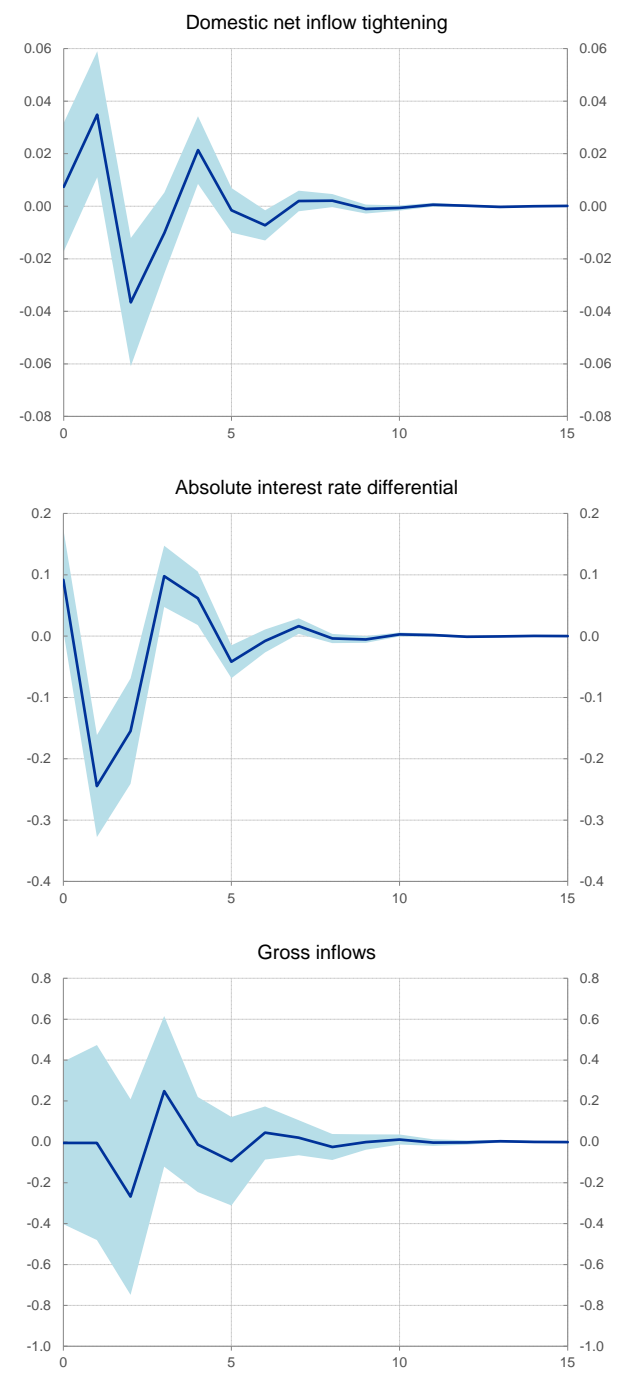
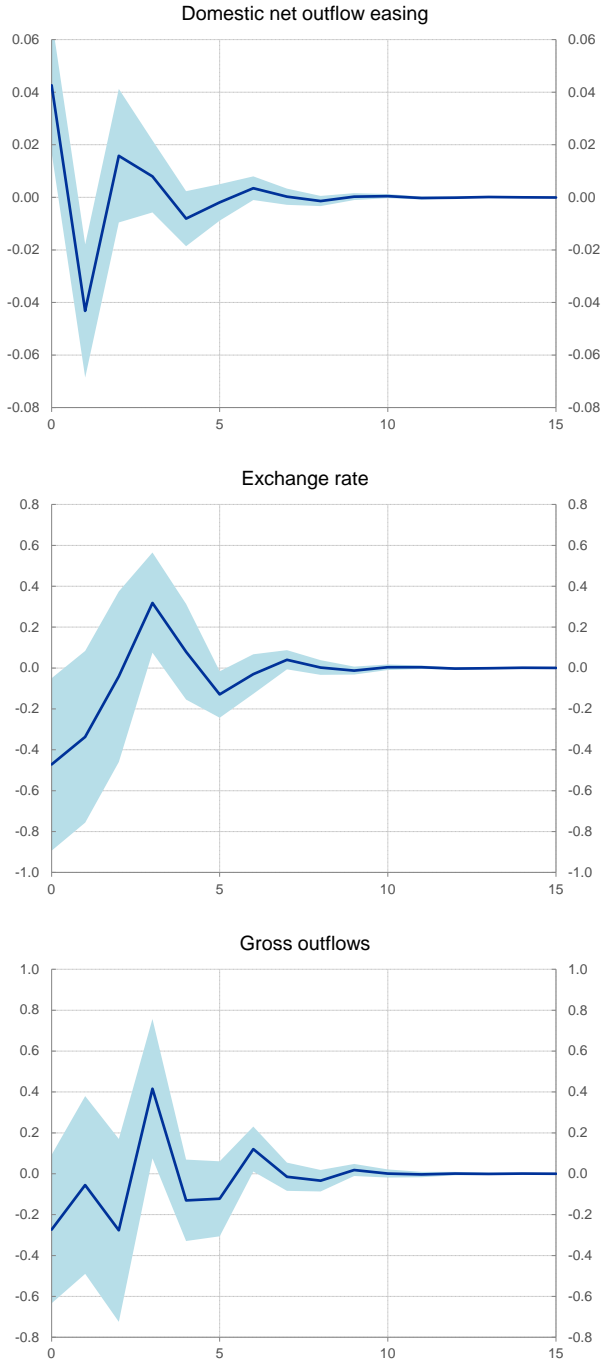

Note: The lines show the impact of a one unit (i.e. one measure) increase in foreign net inflow tightening, using weighted capital control changes. The shaded areas denote the 16 and 84 percentiles. The responses are expressed in the unit of each variable (exchange rate: q-o-q percentage changes; 3-month money market interest rate differential: q-o-q change in the absolute value of the differential, in percentage points; capital flows: q-o-q changes in seasonally-adjusted flows expressed as a percentage of GDP).

Figure 12. Spillover effects pre-crisis (2001Q1-2008Q2) 

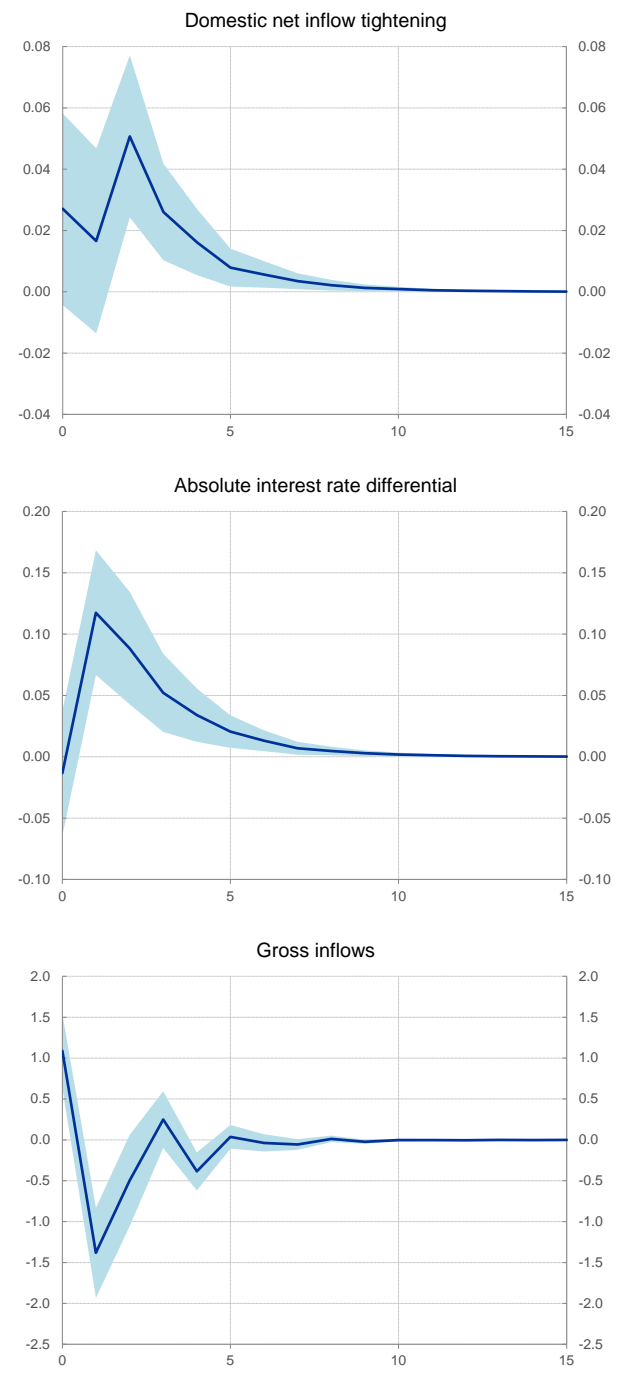
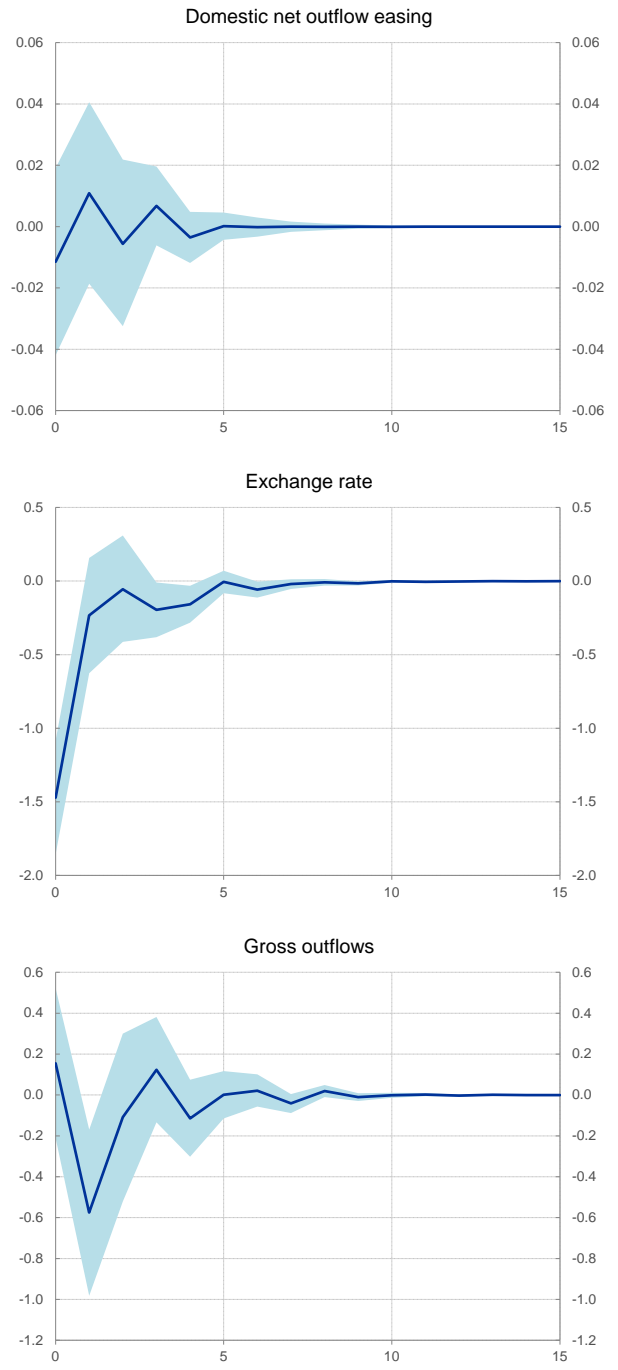

Note: The lines show the impact of a one unit (i.e. one measure) increase in foreign net inflow tightening, using weighted capital control changes. The shaded areas denote the 16 and 84 percentiles. The responses are expressed in the unit of each variable (exchange rate: q-o-q percentage changes; 3-month money market interest rate differential: q-o-q change in the absolute value of the differential, in percentage points; capital flows: q-o-q changes in seasonally-adjusted flows expressed as a percentage of GDP).

Figure 13. Spillover effects post-crisis (2009Q2-2012Q4)

\subsection{Are there differences across countries?}

Spillovers from changes in capital controls seem to be stronger in Latin America than in Asia. Figure 14 shows that net inflow tightening measures in Brazil have a significant impact on net capital inflows and the exchange rate in other Latin American countries, which lasts one quarter. While the increase in capital inflows is more than offset by a decline in the following quarter as the appreciation of the currency is more permanent. To reduce inflow pressure, other countries in Latin America immediately ease capital outflow restrictions, although that does not 
have a significant impact on gross capital outflows. In fact, these flows decline as domestic short-term interest rates increase relative to foreign interest rates.
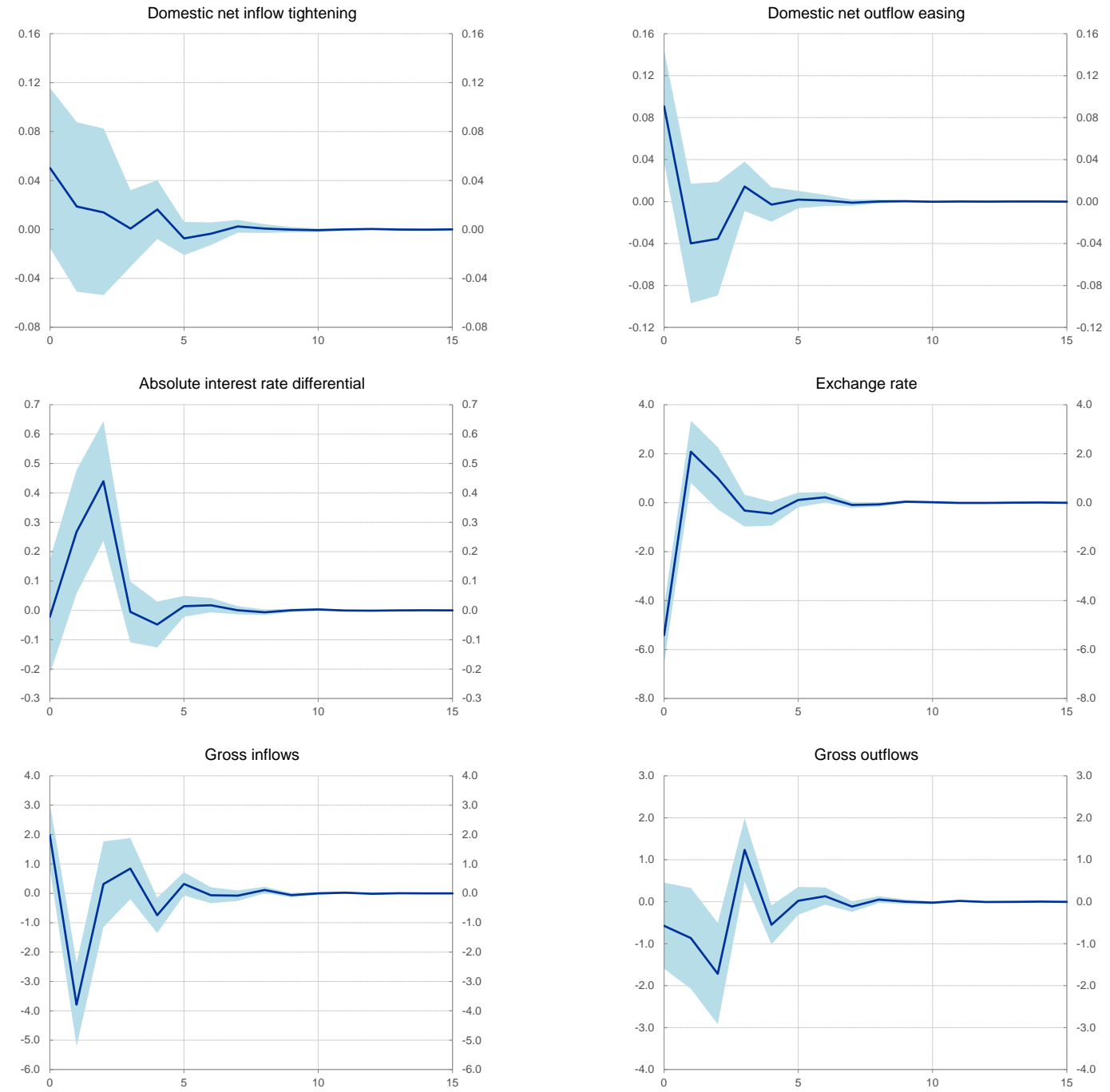

Note: The lines show the impact of a one unit (i.e. one measure) increase in foreign net inflow tightening, using weighted capital control changes. The shaded areas denote the 16 and 84 percentiles. The responses are expressed in the unit of each variable (exchange rate: q-o-q percentage changes; 3-month money market interest rate differential: q-o-q change in the absolute value of the differential, in percentage points; capital flows: q-o-q changes in seasonally-adjusted flows expressed as a percentage of GDP).

Figure 14. Spillover effects: Latin America 

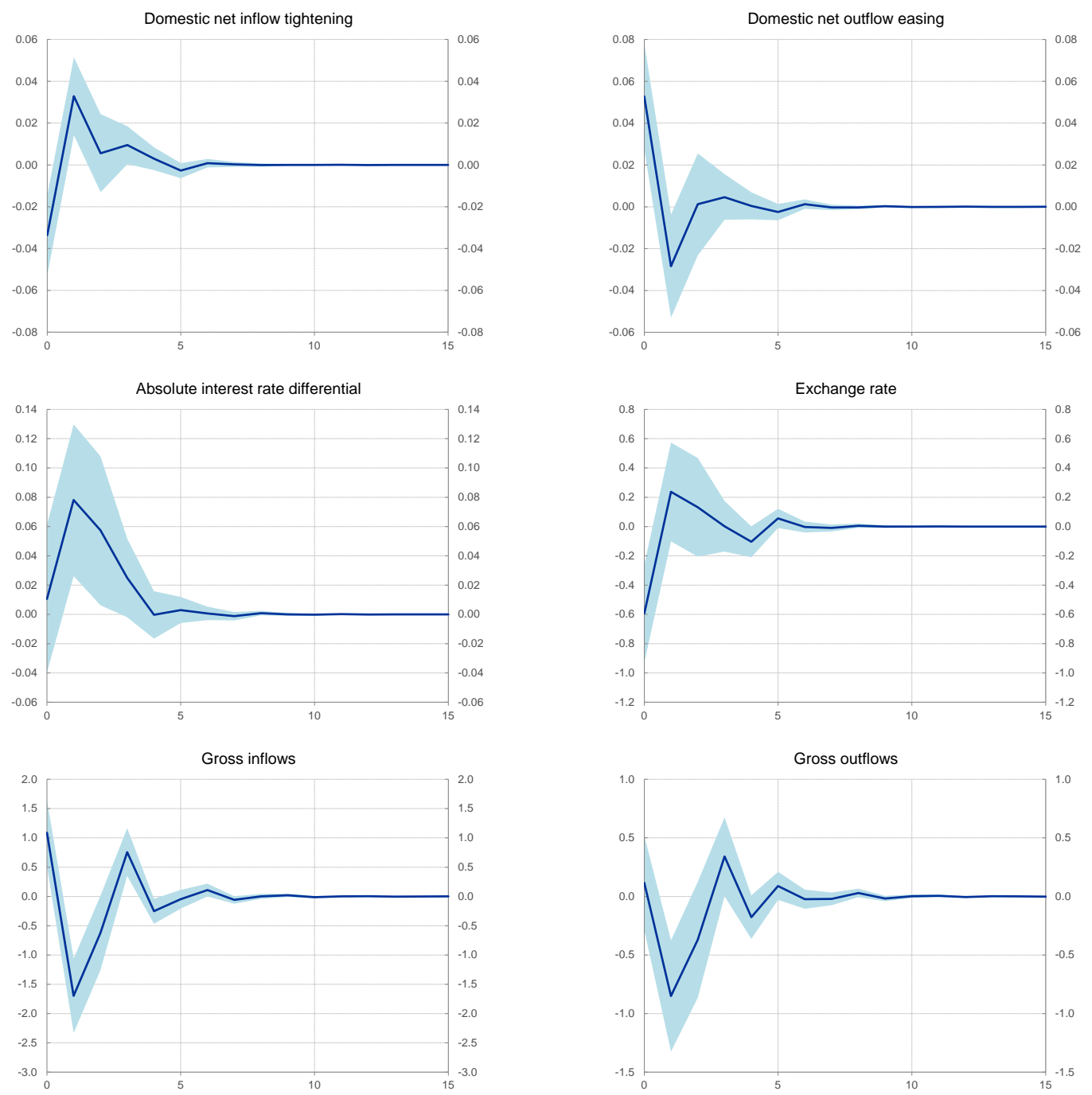

Note: The lines show the impact of a one unit (i.e. one measure) increase in foreign net inflow tightening, using weighted capital control changes. The shaded areas denote the 16 and 84 percentiles. The responses are expressed in the unit of each variable (exchange rate: q-o-q percentage changes; 3month money market interest rate differential: q-o-q change in the absolute value of the differential, in percentage points; capital flows: q-o-q changes in seasonally-adjusted flows expressed as a percentage of GDP).

Figure 15. Spillover effects: Asia

In Asia, we find a similar pattern for spillovers of measures in China/India on the other Asian countries, but the impacts are much smaller than in Latin America (Figure 15). For example, the impact of Brazilian inflow tightening measures on net capital inflows and exchange rates of other Latin American countries is larger (6\% average quarter-on-quarter appreciation in the same quarter) than the impact of inflow tightening measures in India and China on other 
Asian countries (less than 1\% average appreciation in the same quarter). This may reflect the relatively closed capital accounts of China and India as well as other Asian EMEs in the sample relative to Brazil and the other Latin American EMEs. The larger size of the spillovers via exchange rates in Latin America should also be seen in conjunction with the fact that exchange rate fluctuations in most Latin American countries during our sample were larger than those in Asia.

Focusing on spillovers among the five BRICS countries only, we find that multilateral effects among these countries are similar to those for the full sample, with one key difference relating to the domestic policy reaction (Figure 16). Compared to the full sample, there is a stronger domestic tightening of inflow controls in response to the policy actions in other BRICS, and no domestic easing of outflow controls. As in the full sample, this policy reaction leads to a reversal of the initial impact on capital inflows and interest rates and reduced upward pressure on the currency, although the currency appreciation observed immediately after the shock is not offset by a subsequent depreciation. A tightening of inflow controls in BRICS countries therefore not only leads to permanently stronger exchange rates in other, similarly-sized EMEs, but it also triggers an adverse dynamic that results in less open capital accounts.

So far, we have based our results on the full sample or regional sub-samples, assuming that a uniform panel structure can be imposed on all these country groups. As economic and financial structures and policy frameworks differ across countries, we also analyze the spillover effects using country-specific models. These models are more parsimonious since the number of observations in the country-specific samples is much more limited. In the country-specific models we drop two endogenous variables (domestic net outflow easing and gross outflows) and focus on the response of the remaining variables. Table 2 summarizes our results for the individual countries using country-specific structural VARs. The following points are noteworthy. 

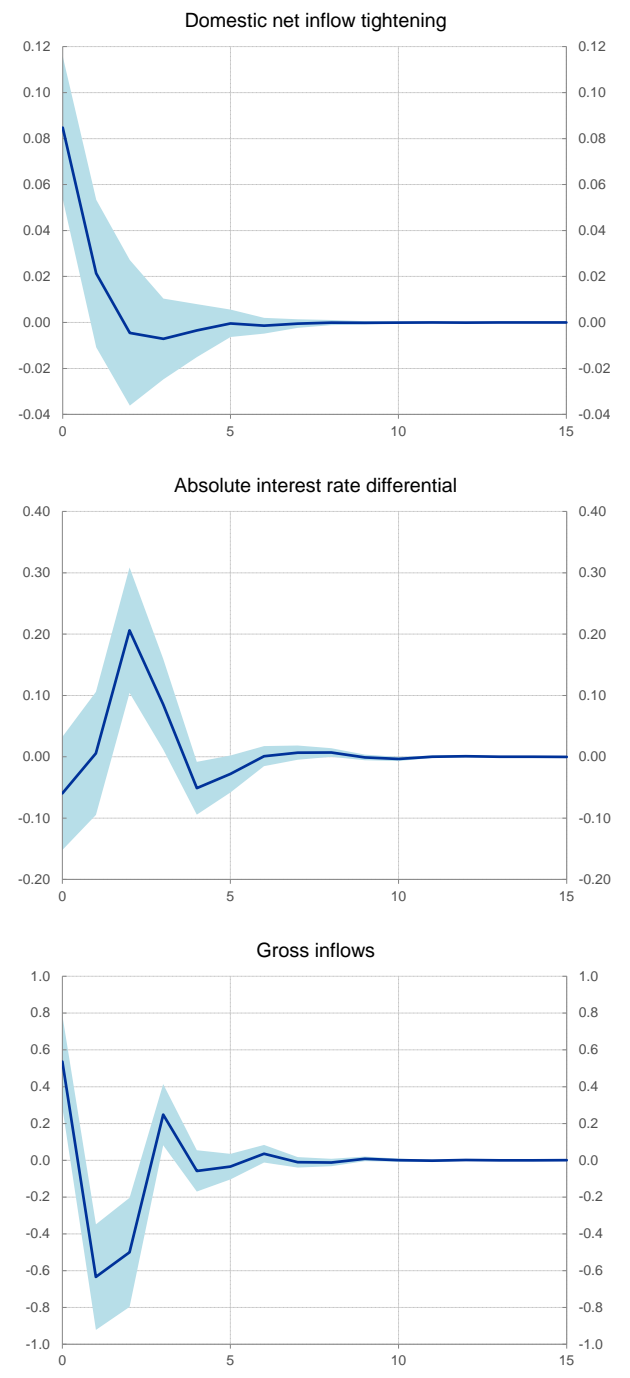
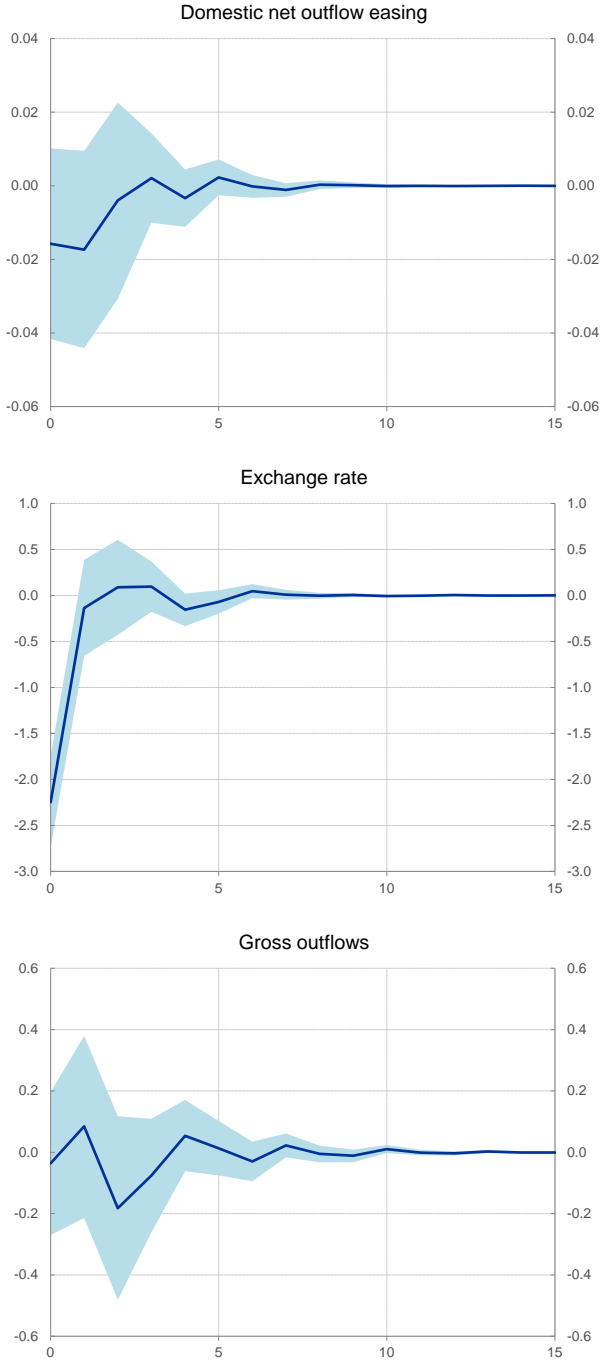

Note: The lines show the impact of a one unit (i.e. one measure) increase in foreign net inflow tightening, using weighted capital control changes. The shaded areas denote the 16 and 84 percentiles. The responses are expressed in the unit of each variable (exchange rate: q-o-q percentage changes; 3-month money market interest rate differential: q-o-q change in the absolute value of the differential, in percentage points; capital flows: q-o-q changes in seasonally-adjusted flows expressed as a percentage of GDP).

Figure 16. Spillover effects: BRICS

First, our analysis for individual countries confirms that the most common channel for spillovers runs via exchange rates rather than capital flows. In fact, for almost all countries shown in Table 2, inflow tightening measures taken in their BRICS neighbors generate significant spillovers via the exchange rate. The key role of exchange rates as a transmission channel for these shocks suggests that, to the extent that they are not accompanied by movements in net capital flows, capital control changes in the BRICS may have an impact on exchange rate 
expectations in other EMEs. The finance literature confirms that exchange rates/prices can adjust without a change in the underlying flows/trades, for example in response to macroeconomic news (see e.g. Froot and Ramadorai, 2005).

\begin{tabular}{l|ccccc}
\hline \multicolumn{5}{c}{} & \multicolumn{5}{c}{ Impact of shock to foreign inflow tightening } & $\begin{array}{c}\text { Wall or } \\
\text { gate? }\end{array}$ \\
\hline & $\begin{array}{c}\text { Exchange } \\
\text { rate }\end{array}$ & $\begin{array}{c}\text { Gross } \\
\text { inflows }\end{array}$ & $\begin{array}{c}\text { Interest rate } \\
\text { differential }\end{array}$ & $\begin{array}{c}\text { Domestic } \\
\text { capital } \\
\text { controls }\end{array}$ & \\
\hline Argentina & $\mathrm{N}$ & $\mathrm{N}$ & $\mathrm{Y}$ & $\mathrm{N}$ & $\mathrm{G}$ \\
Brazil & $\mathrm{Y}$ & $\mathrm{N}$ & $\mathrm{N}$ & $\mathrm{Y}$ & $\mathrm{G}$ \\
Chile & $\mathrm{Y}$ & $\mathrm{N}$ & $(\mathrm{N})$ & $\mathrm{N}$ & $\mathrm{G}$ \\
China & $\mathrm{Y}$ & $\mathrm{N}$ & $\mathrm{N})$ & $\mathrm{Y}$ & $\mathrm{W}$ \\
Colombia & $\mathrm{Y}$ & $\mathrm{N}$ & $(\mathrm{N})$ & $\mathrm{N}$ & $\mathrm{G}$ \\
Indonesia & $(\mathrm{Y})$ & $\mathrm{N}$ & $\mathrm{N}$ & $(\mathrm{Y})$ & $\mathrm{G}$ \\
India & $\mathrm{Y}$ & $\mathrm{Y}$ & $(\mathrm{N})$ & $\mathrm{Y}$ & $\mathrm{W}$ \\
Korea & $\mathrm{N}$ & $\mathrm{N}$ & $\mathrm{N}$ & $\mathrm{N}$ & $\mathrm{G}$ \\
Mexico & $\mathrm{Y}$ & $\mathrm{N}$ & $\mathrm{N}$ & $\mathrm{N}$ & $\mathrm{G}$ \\
Malaysia & $\mathrm{Y}$ & $\mathrm{Y}$ & $(\mathrm{Y})$ & $(\mathrm{N})$ & $\mathrm{W}$ \\
Peru & $\mathrm{Y}$ & $\mathrm{Y}$ & $\mathrm{N}$ & $\mathrm{Y}$ & $\mathrm{G}$ \\
Philippines & $\mathrm{Y}$ & $\mathrm{Y}$ & $\mathrm{N}$ & $(\mathrm{N})$ & $\mathrm{W}$ \\
Russia & $\mathrm{Y}$ & $\mathrm{N}$ & $\mathrm{Y}$ & $\mathrm{Y}$ & $\mathrm{G}$ \\
Thailand & $\mathrm{N}$ & $\mathrm{N}$ & $\mathrm{N}$ & $(\mathrm{N})$ & $\mathrm{W}$ \\
Turkey & $\mathrm{Y}$ & $(\mathrm{N})$ & $\mathrm{N}$ & $\mathrm{N}$ & $\mathrm{G}$ \\
South Africa & $\mathrm{Y}$ & $\mathrm{N}$ & $\mathrm{N}$ & $\mathrm{N}$ & $\mathrm{W}$ \\
\hline
\end{tabular}

This table summarizes the country-specific results. $\mathrm{Y}=$ significant impact with expected sign; $(\mathrm{Y})=$ significant impact with expected sign with delay; $\mathrm{N}=$ no significant impact; $(\mathrm{N})=$ significant impact with unexpected sign. $\mathrm{W}$ = "wall", i.e. a country with extensive and long-standing capital controls; $G=$ "gate", i.e. a country with less extensive controls or practically no controls. This classification is based on Klein and Shambaugh (2015).

Table 2. Spillover effects of BRICS capital control changes on other EMEs

Second, in contrast to earlier findings in the literature, there appears to be no clear relationship between the importance of spillovers and the degree of restrictiveness of the capital account. When we compare our results with the classification of countries into "walls", i.e. countries with extensive and long-standing capital controls and "gates", i.e. countries with less extensive controls (Klein and Shambaugh, 2015), it seems that although most countries for which we find spillovers tend to me more open, there is no clear pattern that sets these countries apart from the economies with more extensive restrictions. 
Finally, we perform a number of robustness checks to our analysis of spillovers. The main results do not change if we use net capital inflows instead of gross flows, exclude FDI from our capital flow definition, drop the seasonal adjustment for capital flows, replace our exchange rate variable with the exchange rate volatility indicator used to analyze domestic effects or when we look at different components of capital flows separately (FDI, portfolio and other investment flows).

\subsection{Summarizing the results for multilateral effects}

To conclude, our evidence suggests that spillover effects of capital flow policies may have been more important than generally thought. We find evidence that during the 2000s and early 2010s capital flow management measures in large EMEs - i.e. tightening of inflow controls - had important implications for other countries. These policies generated upward pressure on the currencies of other EMEs, while in a more limited number of cases they also fueled gross capital inflows to other countries. Spillovers have become larger during the post-crisis period, which could be associated with abundant global liquidity during the years after the crisis and the greater role of retail investment funds during this period (Miyajima and Shim, 2014). We also find evidence of policy spillovers in the sense that policy-makers seem to tighten inflow controls in response to spillovers from other large economies.

\section{Conclusions}

This article evaluates the domestic and multilateral impact of capital controls in emerging market economies since the early 2000s. We investigate the effects of changes in capital account openness by using a new, detailed dataset on capital control changes. Looking at the domestic effects of capital flow measures, our main conclusion is that policy choices in EMEs during the 2000s were shaped by the constraints of the monetary policy trilemma. Steps to dismantle capital account restrictions weakened monetary policy autonomy of EMEs as policy-makers gave priority to exchange rate stability. A more detailed analysis of changes in monetary policy autonomy would require more specific data on the central bank's objectives and the external shocks affecting the economies in question. 
Measures opening the capital account also had a short-lived impact on gross capital flows, although there was no impact on net capital inflows. These findings are consistent with evidence in the literature that, in the past decade, EMEs have become more important as a source of capital in addition to being a recipient of capital, implying that the behavior of net capital flows depends more than in the past on resident flows. Our results thus suggest that resident flows warrant attention when analyzing the impact of capital controls.

As regards spillovers, our main finding is that the cross-border effects of capital flow policies are more important than generally thought. We find clear evidence that during the 2000s net inflow tightening measures in large had significant implications for other countries. Capital flow policies seem to have an impact on other countries via capital flows as well as exchange rates. Spillovers of capital flow policies seem to have become more important over time, as cross-border effects have been larger in the aftermath of the global financial crisis than before the crisis. We also find evidence of policy spillovers in the sense that policy-makers seem to tighten inflow controls in response to a tightening of inflow restrictions in the BRICS. A tightening of inflow controls thus not only leads to economic, but also to policy spillovers that may be sub-optimal. These spillovers point to the potential existence of a coordination problem among countries that use capital controls as an instrument of economic policy. 


\section{References}

Abrigo, M. R. M. and Love I., 2015. Estimation of Panel Vector Autoregression in Stata: a Package of Programs, University of Hawaii Working Paper.

Agenor, P.R. and Hoffmaister A. W., 1998. Capital inflows and the real exchange rate: Analytical framework and econometric evidence, in: R. Glick (ed), Managing Capital Flows and Exchange Rates: Perspectives from the Pacific Basin, Cambridge University Press.

Ahmed, S. and Zlate A., 2014. Capital flows to emerging market economies: A brave new world?, Journal of International Money and Finance, Vol. 48(PB), pp 221-248.

Alpanda, S. and Kabaca S., 2015. International Spillovers of Large Scale Asset Purchases, Bank of Canada Staff Working Paper No. 2015-2.

Aizenman, J., Chinn M.D. and Ito H., 2010. The emerging global financial architecture: tracing and evaluating new patterns of the trilemma configuration, Journal of International Money and Finance, Vol. 29(4), pp 615-641.

Aizenman, J., Chinn M.D. and Ito H., 2016. Monetary policy spillovers and the trilemma in the new normal: Periphery country sensitivity to core country conditions, Journal of International Money and Finance Vol. 68, pp 298-330.

Aizenman, J. and Pasricha G. K., 2013. Why do emerging markets liberalize capital outflow controls? Fiscal versus net capital flow concerns, Journal of International Money and Finance, Vol. 39, pp 1-246.

Baba C. and Kokenyne A., 2011. Effectiveness of Capital Controls in Selected Emerging Markets in the 2000s, IMF Working Paper, WP/11/281.

Bartolini L., and Drazen A., 1997. Capital account liberalization as a signal, American Economic Review, Vol. 87(1), pp 138-154.

Bayoumi T. and Ohnsorge F., 2013. Do Inflows or Outflows Dominate? Global Implications of Capital Account Liberalization in China, IMF Working Paper, WP/13/189.

Beirne J. and Friedrich C., 2014. Capital flows and macroprudential policies: A multilateral assessment of effectiveness and externalities, ECB Working Paper, No 1721.

Binici M., Hutchison M. and Schindler M., 2010. Controlling capital? Legal restrictions and the asset composition of international financial flows, Journal of International Money and Finance, Vol. 29, pp 666-684.

Cardoso E. A. and Goldfajn I., 1998. Capital Flows to Brazil: The Endogeneity of Capital Controls, IMF Staff Paper, Vol. 15, No 1. 
Chantapacdepong P. and Shim I., 2015. Correlations across Asia-Pacific bond markets and the impact of capital flow measures, Pacific-Basin Finance Journal, Vol. 34(C), pp 71-101.

Chinn, M. D. and Ito H., 2008. A New Measure of Financial Openness, Journal of Comparative Policy Analysis, Vol. 10(3), pp 309-322.

De Gregorio J., Edwards S. and Valdes R. O., 2000. Controls on capital inflows: do they work?, Journal of Development Economics, Vol. 63, pp 59-83.

Doan, T., 2009. RATS User’s Manual. Evanston, Ill.: Estima.

Edwards S. and Rigobon R., 2009. Capital controls on inflows, exchange rate volatility and external vulnerability, Journal of International Economics, Vol. 78, pp 256-267.

Fan, M., and Lyons R. K., 2003. Customer Trades and Extreme Events in Foreign Exchange, in: Paul Mizen (ed.), Monetary History, Exchange Rates and Financial Markets: Essays in Honour of Charles Goodhart, Volume Two, Chap. 6, pp 160-179 (Cheltenham: Edward Elgar).

Farhi, E., and Werning I., 2012. Dealing with the Trilemma: Optimal Capital Controls with Fixed Exchange Rates, NBER Working Paper no 18199.

Fernández, A., Klein M., Rebucci A., Schindler M. and Uribe M., 2016. Capital Control Measures: A New Dataset, IMF Economic Review, Vol. 64, Issue 3, pp 548-574.

Forbes K., Fratzscher M., Kostka T. and Straub R., 2016. Bubble thy neighbour: Portfolio effects and externalities from capital controls, Journal of International Economics, Vol. 99, pp 85-104.

Forbes K., Fratzscher M. and Straub R., 2015. Capital-flow management measures: What are they good for?, Journal of International Economics, Vol. 96, pp S76-S97.

Forbes K. and Warnock F., 2012. Capital flow waves: Surges, stops, flight, and retrenchment, Journal of International Economics, Vol. 88, pp 235-251.

Froot, K. and Ramadorai T., 2005. Currency Returns, Intrinsic Value, and Institutional-Investor Flows, Journal of Finance, Vol. LX, 3, pp 1535-1566.

Giordani P., Ruta M., Weisfeld H. and Zhu L., 2017. Capital Flow Deflection, Journal of International Economics, Vol. 105, pp 102-118.

Gyntelberg J., Loretan M. and Subhanij T., 2018. Private information, capital flows, and exchange rates, Journal of International Money and Finance, Vol. 81, pp 40-55.

Hutchison, M., Pasricha G. K. and Singh N., 2013. Effectiveness of Capital Controls in India: Evidence from the Offshore NDF Market, IMF Economic Review, Vol. 60, 3, pp 395-438. 
International Monetary Fund, 2011a. Recent experiences in managing capital inflows: Crosscutting themes and possible framework, IMF Policy Paper, February.

International Monetary Fund, 2011b. International Capital flows: Reliable or Fickle?, World Economic Outlook, Chapter 4, April 2011.

Jinjarak, Y., Noy I., and Zheng H., 2013. Capital controls in Brazil: Stemming a tide with a signal?, Journal of Banking and Finance, Vol. 37(8), pp 2938-2952.

Karolyi, G. A., Ng D. T., and Prasad E. S., 2013. The Coming Wave, HKIMR Working Paper No.08/2013.

Klein M. W. and J. C. Shambaugh (2015), "Rounding the Corners of the Policy Trilemma: Sources of Monetary Policy Autonomy”, American Economic Journal: Macroeconomics, Vol. 7(4), pp 33-66.

Koop, G., 2003. Bayesian econometrics, J Wiley and Sons, Sussex, England.

Lambert, F., Ramos-Tallada F. and Rebillard C., 2011. Capital controls and spillover effects: evidence from Latin-American countries, Banque de France Working Paper No. 357.

Lane P. R. and Milesi-Ferretti G. M., 2007. The external wealth of nations mark II: Revised and extended estimates of foreign assets and liabilities, 1970-2004, Journal of International Economics, Vol. 73, pp 223-250.

Magud N. E., Reinhart C. M. and Rogoff K. S., 2011. Capital Controls: Myth and Reality - A Portfolio Balance Approach, NBER Working Paper 16805.

Miniane J. and Rogers J. H., 2007. Capital Controls and the International Transmission of U.S. Money Shocks, Journal of Money, Credit and Banking, Vol. 39(5), pp 1003-1035.

Miyajima K. and Shim I., 2014. Asset managers in emerging market economies, BIS Quarterly Review, September 2014.

Obstfeld, M., Shambaugh J. C., and Taylor A. M., 2005. The Trilemma in History: Tradeoffs among Exchange Rates, Monetary Policies, and Capital Mobility, Review of Economics and Statistics, Vol. 87 (August), pp 423- 38.

Olson E., Miller S. and Wohar M. E., 2012. “Black Swans” before the “Black Swan” evidence from international LIBOR-OIS spreads, Journal of International Money and Finance, Vol. 31, pp 1339-1357.

Pasricha, G. K., 2012. Measures to manage capital flows in emerging market economies, North American Journal of Economics and Finance, special issue on "International Finance in the aftermath of the 2008 Global Crisis”, Vol. 23(3), pp 286-309. 
Pasricha, G. K., 2017. Policy rules for Capital Controls, BIS Working Paper No. 670, 9 November 2017.

Peersman G., 2004, The Transmission of Monetary Policy in the Euro Area: Are the Effects Different Across Countries?, Oxford Bulletin of Economics and Statistics, Vol. 66(3), pp 285308.

Pandey R., Pasricha G. K., Patnaik I. and Shah A., 2015. Motivations for capital controls and their effectiveness, Bank of Canada Working Paper No. 2015-5.

Rey, H., 2017. Discussion of Cerutti, Claessens and Rose, 2017. Presentation available at: http://www.helenerey.eu/Content/_Documents/NBERdiscussion2017web1HR.pdf

Schindler M., 2009. Measuring Financial Integration: A New Data Set, IMF Staff Papers, Vol. 56(1), pp 222-238.

Saborowski C., Sanya S., Weisfeld H. and Yepez J., 2014. Effectiveness of Capital Outflow Restrictions, IMF Working Paper WP/14/8.

Tapia M., 2017. Challenges to Monetary Policy in a Small Open Economy, presentation at Roundtable “Are we heading for a new monetary order and new monetary policy regime?", Vienna, 5 September 2017.

Schmitt-Grohe, S., and Uribe M., 2012. Prudential Policy for Peggers, NBER Working Paper 18031.

Valdés-Prieto, S., and Soto M., 1998. The Effectiveness of Capital Controls: Theory and Evidence from Chile, Empirica, Vol. 25(2), pp 133-164.

Vegh, C.A., 2017. The monetary policy dilemma in LAC: Coming back to a Central Bank near you, presentation at the 9th Annual Conference organized by the Central Reserve Bank of Peru and the Reinventing Bretton Woods Committee, Cuzco, 24-25 July 2017.

Zellner, A., 1962. An efficient method of estimating seemingly unrelated regressions and tests of aggregation bias, Journal of American Statistical Association, Vol. 57(298), pp 348-368. 


\section{Appendix \\ Table A1: Variables used in the baseline model}

\begin{tabular}{|c|c|}
\hline Variable & Description/Source \\
\hline Gross inflows & $\begin{array}{l}\text { Gross inflows are gross private capital inflows, computed as the sum of } \\
\text { portfolio investment inflows, other investment inflows (excluding monetary } \\
\text { authority and government flows), derivative inflows, and FDI inflows. The } \\
\text { series are seasonally adjusted (using the Census X12 method) and expressed as } \\
\text { a share of domestic GDP. In the regressions this variable is included as the q-o- } \\
\text { q change in seasonally-adjusted flows expressed as a percentage of GDP. } \\
\text { Source: IMF-BOPS. }\end{array}$ \\
\hline Gross outflows & $\begin{array}{l}\text { Gross outflows are gross private capital outflows, computed as the sum of } \\
\text { portfolio investment outflows, other investment outflows (excluding monetary } \\
\text { authority and government flows), derivative outflows, and FDI outflows. The } \\
\text { series are seasonally adjusted (using the Census X12 method) and expressed as } \\
\text { a share of domestic GDP. In the regressions this variable is included as the q-o- } \\
\text { q change in seasonally-adjusted flows expressed as a percentage of GDP. } \\
\text { Source: IMF-BOPS. }\end{array}$ \\
\hline $\begin{array}{l}\text { Absolute value of the interest rate } \\
\text { differential (monetary policy } \\
\text { autonomy index) }\end{array}$ & $\begin{array}{l}\text { The proxy for monetary policy autonomy is computed as the absolute value of } \\
\text { the differential between the domestic short-term interest rate and the US short- } \\
\text { term interest rate (both expressed as a percentage per annum). The interest rates } \\
\text { used are short-term interest rates from Oxford Economics, except Colombia } \\
\text { (90-day CD rates from the Banco de la Republica) and Peru (IMF-IFS money } \\
\text { market rate). The US interest rate is the three-month USD LIBOR. In the } \\
\text { regressions this variable is included as the q-o-q change. Source: Datastream. }\end{array}$ \\
\hline Spot exchange rate vs the USD & $\begin{array}{l}\text { The spot exchange rate is expressed as the number of units of the local currency } \\
\text { per US dollar, with an increase implying a depreciation of the local currency. In } \\
\text { the regressions it is included as the q-o-q percentage change. Source: } \\
\text { Bloomberg. }\end{array}$ \\
\hline Exchange rate volatility & $\begin{array}{l}\text { The exchange rate volatility is computed as the standard deviation of the log of } \\
\text { the daily spot exchange rate vis-à-vis the US dollar. In the regressions this } \\
\text { variable is included as the q-o-q change of the standard deviation. }\end{array}$ \\
\hline Bank credit growth & $\begin{array}{l}\text { It is computed as the } y-0-y \text { growth rate of bank credit to the non-financial } \\
\text { private sector. Source: BIS. }\end{array}$ \\
\hline US GDP growth & $\begin{array}{l}\text { The y-o-y growth rate of US real GDP in percent. Source: Bureau of Economic } \\
\text { Analysis. }\end{array}$ \\
\hline US short term interest rate & $\begin{array}{l}\text { US federal funds rate. From 2009Q1 onwards: Wu-Xia shadow federal funds } \\
\text { rate. Source: FRED. }\end{array}$ \\
\hline Crude oil price & Crude oil price index in USD (2005=100). Source: IMF-IFS. \\
\hline
\end{tabular}

Table A2: Summary statistics of global variables

\begin{tabular}{lcccc}
\hline \hline & Mean & Standard Deviation & Maximum & Minimum \\
\hline US GDP growth & 1.71 & 1.90 & 4.41 & -4.06 \\
US short term rate & 1.64 & 2.20 & 5.34 & -1.47 \\
Crude oil price & 117.67 & 57.16 & 227.25 & 36.22 \\
\hline
\end{tabular}


Table A3: Summary statistics of country-specific variables

\begin{tabular}{l|cccccccccccc}
\hline \hline & \multicolumn{4}{c}{ Gross inflows } & \multicolumn{3}{c}{ Gross outflows } & \multicolumn{4}{c}{ Abs. value of the interest rate diff. } \\
\hline & mean & sd & max & min & mean & sd & max & min & mean & sd & max & min \\
\hline ARG & -0.07 & 4.35 & 14.98 & -15.04 & -0.02 & 2.51 & 4.17 & -8.33 & 0.32 & 1.14 & 4.02 & -1.29 \\
BRA & 0.04 & 4.16 & 7.33 & -12.00 & 0.05 & 2.53 & 6.71 & -5.97 & -0.07 & 1.65 & 4.63 & -5.09 \\
CHL & -0.01 & 8.15 & 13.77 & -25.48 & -0.05 & 7.29 & 13.14 & -15.89 & 0.05 & 0.88 & 2.51 & -2.82 \\
CHN & -0.06 & 3.36 & 7.01 & -8.64 & -0.05 & 3.99 & 11.22 & -8.76 & 0.06 & 0.62 & 1.57 & -1.73 \\
COL & 0.01 & 4.89 & 17.09 & -19.84 & -0.04 & 5.50 & 21.68 & -20.80 & -0.06 & 0.75 & 2.45 & -2.31 \\
IDN & 0.29 & 2.73 & 4.54 & -9.59 & 0.07 & 1.90 & 4.41 & -4.76 & -0.11 & 1.18 & 3.11 & -1.86 \\
IND & 0.13 & 2.34 & 4.60 & -4.49 & 0.02 & 1.43 & 3.11 & -3.90 & 0.07 & 0.93 & 2.61 & -2.12 \\
KOR & 0.01 & 7.02 & 26.15 & -30.64 & 0.06 & 4.22 & 11.36 & -18.62 & 0.04 & 0.47 & 1.78 & -1.16 \\
MEX & 0.11 & 3.88 & 8.42 & -10.43 & 0.09 & 3.64 & 10.72 & -7.90 & -0.18 & 0.97 & 1.75 & -3.76 \\
MYS & 0.45 & 12.46 & 25.56 & -31.05 & 0.18 & 7.49 & 16.37 & -17.16 & 0.00 & 0.37 & 0.56 & -1.29 \\
PER & 0.22 & 5.79 & 13.89 & -14.03 & 0.04 & 2.96 & 7.11 & -10.65 & -0.02 & 1.91 & 6.85 & -9.44 \\
PHL & 0.24 & 5.67 & 11.48 & -13.84 & 0.06 & 6.15 & 13.90 & -15.98 & -0.06 & 0.83 & 3.69 & -3.11 \\
RUS & 0.19 & 4.85 & 7.31 & -18.28 & 0.06 & 5.98 & 9.78 & -20.20 & -0.16 & 2.63 & 11.24 & -6.75 \\
THA & 0.18 & 8.20 & 31.99 & -19.48 & 0.01 & 8.27 & 19.26 & -30.93 & 0.00 & 0.42 & 0.90 & -1.28 \\
TUR & 0.14 & 3.81 & 5.22 & -14.43 & 0.02 & 3.06 & 5.29 & -6.44 & -0.46 & 1.95 & 6.58 & -4.43 \\
ZAF & 0.01 & 5.02 & 13.53 & -12.46 & -0.23 & 5.31 & 11.47 & -13.06 & -0.01 & 0.91 & 2.20 & -2.60 \\
\hline
\end{tabular}

Note: $\mathrm{sd}=$ standard deviation, $\max =$ maximum, $\min =$ minimum. The descriptive statistics relate to the transformed variables, as explained in Table A1. 
Table A4: Summary statistics of country-specific variables

\begin{tabular}{l|cccccccccccc}
\hline \hline \multicolumn{3}{c}{ Exchange rate volatility } & \multicolumn{3}{c}{ Spot exchange rate } & \multicolumn{3}{c}{ Bank credit } \\
\hline & mean & sd & max & min & mean & sd & max & min & mean & sd & max & min \\
\hline ARG & 0.01 & 0.63 & 1.66 & -1.51 & 1.45 & 2.47 & 7.44 & -5.03 & 28.18 & 13.73 & 50.35 & -8.56 \\
BRA & -0.04 & 2.03 & 4.93 & -4.57 & 0.61 & 11.17 & 43.97 & -14.47 & 19.41 & 7.25 & 32.37 & 6.41 \\
CHL & -0.03 & 1.23 & 2.97 & -1.88 & -0.13 & 6.95 & 31.12 & -10.02 & 11.79 & 5.90 & 21.29 & -1.42 \\
CHN & 0.01 & 0.24 & 0.90 & -0.82 & -0.59 & 0.96 & 1.23 & -3.63 & 16.79 & 6.91 & 34.20 & 2.26 \\
COL & 0.00 & 1.70 & 4.38 & -4.41 & -0.24 & 6.98 & 33.22 & -15.16 & 14.54 & 9.22 & 33.87 & -3.53 \\
IDN & -0.07 & 2.15 & 6.66 & -7.20 & 0.22 & 6.07 & 27.13 & -14.02 & 21.67 & 8.20 & 36.51 & 1.09 \\
IND & 0.03 & 0.93 & 2.74 & -2.23 & 0.41 & 4.39 & 18.37 & -5.78 & 19.72 & 5.88 & 33.21 & 9.38 \\
KOR & -0.01 & 1.31 & 3.15 & -2.39 & -0.11 & 7.08 & 38.98 & -10.19 & 8.39 & 4.95 & 18.92 & 0.03 \\
MEX & 0.00 & 1.14 & 4.18 & -3.15 & 0.78 & 6.39 & 34.09 & -5.80 & 10.39 & 12.50 & 32.11 & -12.87 \\
MYS & 0.01 & 0.51 & 1.33 & -1.15 & -0.43 & 2.61 & 10.31 & -6.03 & 7.80 & 2.75 & 13.56 & 4.18 \\
PER & 0.01 & 0.55 & 1.67 & -1.20 & -0.64 & 2.36 & 8.70 & -5.41 & 10.83 & 10.46 & 32.09 & -8.81 \\
PHL & -0.06 & 0.72 & 1.50 & -1.65 & -0.31 & 3.37 & 10.80 & -6.51 & 7.66 & 6.56 & 26.16 & -2.42 \\
RUS & 0.00 & 1.41 & 3.68 & -3.07 & 0.21 & 5.68 & 23.02 & -7.36 & 32.56 & 15.33 & 53.35 & -2.45 \\
THA & -0.03 & 0.96 & 1.81 & -2.93 & -0.66 & 3.36 & 6.43 & -7.15 & 6.65 & 6.28 & 17.31 & -12.03 \\
TUR & -0.06 & 2.22 & 7.86 & -5.77 & 1.19 & 8.60 & 37.89 & -9.85 & 35.26 & 15.98 & 68.06 & 2.65 \\
ZAF & 0.00 & 2.62 & 7.86 & -8.39 & 0.73 & 10.60 & 47.34 & -14.49 & 13.05 & 7.84 & 25.70 & 0.97 \\
\hline
\end{tabular}

Note: $\mathrm{sd}=$ standard deviation, $\max =$ maximum, $\min =$ minimum. The descriptive statistics relate to the transformed variables, as explained in Table A1. 